\title{
Subauroral red arcs as a conjugate phenomenon: comparison of OV1-10 satellite data with numerical calculations
}

\author{
A. V. Pavlov \\ Institute of Terrestrial Magnetism, Ionosphere and Radio-Wave Propagation, Russia Academy of Science. (IZMIRAN), Troitsk,
} Moscow Region, 142092, Russia

Received: 14 October 1996 / Revised: 3 March 1997 / Accepted: 11 March 1997

\begin{abstract}
This study compares the OV1-10 satellite measurements of the integral airglow intensities at $630 \mathrm{~nm}$ in the SAR arc regions observed in the northern and southern hemisphere as a conjugate phenomenon, with the model results obtained using the time-dependent one-dimensional mathematical model of the Earth ionosphere and plasmasphere (the IZMIRAN model) during the geomagnetic storm of the period 15-17 February 1967. The major enhancements to the IZMIRAN model developed in this study are the inclusion of $\mathrm{He}^{+}$ions (three major ions: $\mathrm{O}^{+}, \mathrm{H}^{+}$, and $\mathrm{He}^{+}$, and three ion temperatures), the updated photochemistry and energy balance equations for ions and electrons, the diffusion of $\mathrm{NO}^{+}$and $\mathrm{O}_{2}^{+}$ions and $\mathrm{O}\left({ }^{1} \mathrm{D}\right)$ and the revised electron cooling rates arising from their collisions with unexcited $\mathrm{N}_{2}, \mathrm{O}_{2}$ molecules and $\mathrm{N}_{2}$ molecules at the first vibrational level. The updated model includes the option to use the models of the Boltzmann or nonBoltzmann distributions of vibrationally excited molecular nitrogen. Deviations from the Boltzmann distribution for the first five vibrational levels of $\mathrm{N}_{2}$ were calculated. The calculated distribution is highly nonBoltzmann at vibrational levels $v>2$ and leads to a decrease in the calculated electron density and integral intensity at $630 \mathrm{~nm}$ in the northern and southern hemispheres in comparison with the electron density and integral intensity calculated using the Boltzmann vibrational distribution of $\mathrm{N}_{2}$. It is found that the intensity at $630 \mathrm{~nm}$ is very sensitive to the oxygen number densities. Good agreement between the modeled and measured intensities is obtained provided that at all altitudes of the southern hemisphere a reduction of about factor 1.35 in MSIS-86 atomic oxygen densities is included in the IZMIRAN model with the non-Boltzmann vibrational distribution of $\mathrm{N}_{2}$. The effect of using of the $\mathrm{O}\left({ }^{1} \mathrm{D}\right)$ diffusion results in the decrease of $4-6 \%$ in the calculated integral intensity of the northern hemisphere and $7-13 \%$ in the calculated integral intensity of the southern hemisphere. It is found that the modeled intensities of the southern hemisphere are more sensitive to the assumed values of the rate coefficients of $\mathrm{O}^{+}\left({ }^{4} \mathrm{~S}\right)$
\end{abstract}

ions with the vibrationally excited nitrogen molecules and quenching of $\mathrm{O}^{+}\left({ }^{2} \mathrm{D}\right)$ by atomic oxygen than the modeled intensities of the northern hemisphere.

\section{Introduction}

During large magnetic storms characterized by a geomagnetic planetary index $K_{p}$ of 5 or greater, stable auroral red (SAR) arcs are observed optically on the equatorward edge of the mid-latitude ionospheric trough in both the northern and southern hemispheres on approximately the same L-shell value of the geomagnetic field (Rees and Roble, 1975). A major part of ground and satellite observations that determine the properties of the SAR arcs have been obtained in the northern hemisphere. The observed SAR-arc properties in magnetically conjugate hemispheres were discussed only by LaValle and Elliott (1972) using OV1-10 satellite data on 16 February 1967, and Reed and Blamont (1968), who determined the positions of the SAR arcs on 28-29 September 1967 using data from the satellite Ogo 4. In this paper we present the results of the first calculations and studies of the SAR arc properties in magnetically conjugate hemispheres for 16-17 February 1967.

The ring current is a prime candidate as the energy source responsible for maintenance of 630-nm emission (Cole, 1965; Rees and Roble, 1975; Kozyra and Nagy, 1991). Several excitation mechanisms have been proposed to account for the heating of the electron gas in the SAR arc region (Cole, 1965; Cornwall et al., 1971; Rees and Roble, 1975; Kozyra et al., 1987; Kozyra and Nagy, 1991; Thorne and Horne, 1992; Horne and Thorne, 1993). Unfortunately, the theory of these mechanisms is very complicated and we cannot use simple equations for the additional heating rate of the electron gas. To model the SAR arc during the 18 December 1971 magnetic storm, a simple model, without any additional heating rate of the electron gas 
during the main phase and with the constant additional heating rate during the recovery phase of geomagnetic storm, was employed by Pavlov (1996). This approach with some modification is used in our model to carry out a comprehensive study of the response of the ionosphere and the integral airglow intensities, $I_{630}$, at $630 \mathrm{~nm}$ in the SAR arc regions to the 15-17 February 1967 geomagnetic storm.

In earlier theoretical studies, Newton et al. (1974) and Pavlov (1989) found that deviation from a Boltzmann distribution of $\mathrm{N}_{2}(v)$ was large in the SAR-arc region at vibrational energy levels $v>2$, and this deviation significantly affected the loss rate of the $\mathrm{O}^{+}\left({ }^{4} \mathrm{~S}\right)$ ions at $\mathrm{F} 2$ region altitudes. The model used in this study gives an opportunity to examine the effect of a non-Boltzmann distribution of $\mathrm{N}_{2}(v)$ on the electron densities and temperatures in the SAR-arc regions of magnetically conjugate hemispheres with the result in the integral airglow intensities at $630 \mathrm{~nm}$.

It has been suggested in a large number of modeling studies that semi-empirical models of the neutral atmosphere (e.g., MSIS) misrepresent true atomic oxygen and molecular nitrogen number densities and neutral temperatures in SAR-arc regions (Kozyra et al., 1982, 1990; Slater et al., 1987; Pavlov, 1996). In this paper we examine the sensitivity of the model results to important atmospheric parameters of the northern and southern hemispheres.

Previous calculations of $\mathrm{O}\left({ }^{1} \mathrm{D}\right)$ number densities have assumed the formation of $\mathrm{O}\left({ }^{1} \mathrm{D}\right)$ in the atmosphere due to production and loss reactions of $\mathrm{O}\left({ }^{1} \mathrm{D}\right)$, without taking into account the diffusion of $\mathrm{O}\left({ }^{1} \mathrm{D}\right)$. An important aim of this paper is to study the role of the diffusion of $\mathrm{O}\left({ }^{1} \mathrm{D}\right)$ in the SAR arc regions.

\section{Theoretical model}

The mathematical model of the thermal plasma in the ionosphere and plasmasphere (the enhanced and improved IZMIRAN model) employed in our calculations is presented in the Appendix. This model includes the option to use models A, B, or C of the rate coefficients of $\mathrm{O}^{+}\left({ }^{4} \mathrm{~S}\right)$ ions with the vibrationally excited nitrogen molecules and quenching of $\mathrm{O}^{+}\left({ }^{2} \mathrm{D}\right)$ by atomic oxygen described in the Appendix. In this study we employ model A and compare results with those from models B and $\mathrm{C}$ to evaluate the effects of the uncertainties in these rate coefficients on calculated integral airglow intensities at $630 \mathrm{~nm}$ in the SAR-arc regions. We have no information on hmF2 and thus can use neither the method developed by Richards (1991) nor our modification of it (Pavlov and Buonsanto, 1997) to calculate an equivalent plasma drift velocity. To overcome this problem, we use the approach of Eqs. (A4-A7) described in the Appendix. In this paper we will examine the effect of the non-Boltzmann distribution of $\mathrm{N}_{2}(v)$ (by solving the system Eq. (A19-A20) of the Appendix) on the integral airglow intensities at $630 \mathrm{~nm}$ in the SARarc regions in comparison with the Boltzmann distribution of $\mathrm{N}_{2}(v)$ given by Eq. (A23) of the Appendix.
One of the inputs for the IZMIRAN model is the additional heating rate, $P_{r c}$, of the electron gas in Eq. (A10) of the Appendix. At the present time, waveparticle interactions (Thorne and Horne, 1992; Erlandson et al., 1993; Horne and Thorne, 1993) and Coulomb collisions between ring-current ions (Cole, 1965; Kozyra et al., 1987; Slater et al., 1987; Kozyra and Nagy, 1991; Fok et al., 1995a,b, 1993) and plasmaspheric electrons and ions are the most plausible mechanisms used to explain electron temperature enhancements and the associated SAR arcs. The present work addresses the contribution from this latter process.

The rate of energy transfer from the energetic ringcurrent ions to plasmaspheric electrons due to Coulomb collisions has been discussed extensively by Kozyra et al. (1987). There is no information available on the ringcurrent population for this storm, and we are therefore forced to assume a heating rate function. It can be found from Eq. (4) in Kozyra et al. (1987) that the value of $P_{r c}$ is proportional to $N_{e} \cdot T_{e}^{-1 / 2}$, where $N_{e}$ is the electron number density and $T_{e}$ is the electron temperature of the plasmasphere. Therefore we selected the additional heating rate as

$P_{r c}(s, t)=f(s, t) \cdot C_{0} \cdot N_{e}(s, t) \cdot T_{e}(s, t)^{-1 / 2}$,

where $f(s, t)=0$ for $s>s_{0}$ and $s<-s_{0} ; f(s, t)=0$ for $t<t_{0} ; f(s, t)=1$ for $-s_{0}<s<s_{0}$ and $t \geq t_{0} ; t$ is local time; $s$ is the distance along the magnetic field line, positive in the direction north to south. The values of $C_{0}, t_{0}$, and $s_{0}$ are selected so that agreement between the measured and the modeled integral airflow intensities at $630 \mathrm{~nm}$ is obtained.

\section{Storm of 15-17 February 1967}

The 15-17 February 1967 geomagnetic storm occurred during medium solar activity $(\mathrm{F} 10.7=126$ and 125$)$. The period of magnetic disturbance started with a sudden commencement at 23:48 UT on 15 February. The recovery phase of this geomagnetic storm began near 14:00 UT 16 February with the index Dst $=-130$ $\gamma$. The observations of the intensities (as an excess above a background nightglow level), $I_{630}$, of the 630$\mathrm{nm}$ oxygen emission in the SAR-arc regions were made by the OV1-10 photometer on 16 February 1967 at 16:26 UT (21:47 LT) in the northern hemisphere at geographic latitude $62.95^{\circ}$ and geographic longitude $80^{\circ}$ (L-shell value of the geomagnetic field is 2.72, $\left.I_{630}=645 \mathrm{R}\right)$ and at $16: 01 \mathrm{UT}(22: 15 \mathrm{LT})$ in the southern hemisphere at geographic latitude $-42.37^{\circ}$ and geographic longitude $93^{\circ}\left(\mathrm{L}=2.83, I_{630}=510 \mathrm{R}\right)$ (LaValle and Elliott, 1972). Although the L-shells were not precisely coincident, the difference $\Delta \mathrm{L}=0.11$ is very small and is the order of accuracy of the location determination (LaValle and Elliott, 1972). Therefore, our calculations were carried out along the geomagnetic field line at $\mathrm{L}=2.72$ from 10:00 LT on 15 February to 04:00 LT on 17 February (this is local time for the northern hemisphere). 

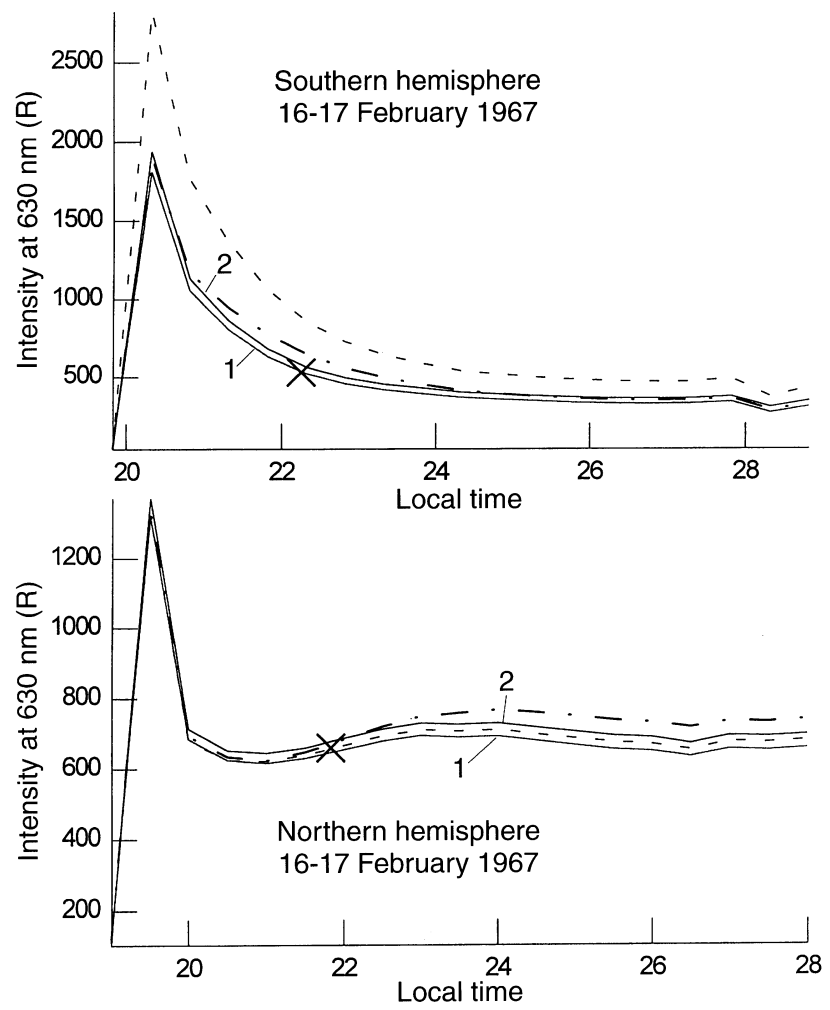

Fig. 1. The time variations of the modeled integral airglow intensities at $630 \mathrm{~nm}$ in the SAR-arc regions in the northern (bottom panel) and southern (top panel) hemispheres at $\mathrm{L}=2.72$ for the recovery phase of the 16-17 February 1967 magnetic storm. Crosses are the integral intensities at $630 \mathrm{~nm}$ in the SAR-arc regions measured by the OV1-10 photometer. The solid and dashed-dotted lines represent the integral intensities from the IZMIRAN model when the MSIS-86 atomic oxygen densities were decreased by a factor of 1.35 during the storm period in the southern hemisphere, and dashed lines are the intensities with the original MSIS-86 atomic oxygen densities. The modeled results were obtained using the Boltzmann vibrational distribution of $\mathrm{N}_{2}(j)$ (dashed-dotted lines) and the non-Boltzmann populations of the first five vibrational levels by solving the $\mathrm{N}_{2}(j=1--5)$ timedependent continuity equations (solid and dotted lines). The solid line 1 and the solid and dotted lines show results when the diffusion of $\mathrm{O}\left({ }^{1} \mathrm{D}\right)$ was included in the IZMIRAN model, and the solid line 2 shows those without the effects of the diffusion of $\mathrm{O}\left({ }^{1} \mathrm{D}\right)$ on $\left[\mathrm{O}\left({ }^{1} \mathrm{D}\right)\right]$. The model $\mathrm{A}$ of the rate coefficients of $\mathrm{O}^{+}\left({ }^{4} \mathrm{~S}\right)$ ions with the vibrationally excited nitrogen molecules and quenching of $\mathrm{O}^{+}\left({ }^{2} \mathrm{D}\right)$ by atomic oxygen was used in the IZMIRAN model

It seems that red arc emission is usually detected during the recovery phase of geomagnetic storms (Rees and Roble, 1975) and we believe that $t_{0}$ in Eq. (1) is close to the starting time of the recovery phase. Previous work concerning the rate of energy transfer from the energetic ring-current ions to plasmaspheric electrons has assumed that the region $-s_{0}<s<s_{0}$ was in plasmasphere above $5000 \mathrm{~km}$ (Pavlov, 1996). For the purposes of this paper this region is taken to be above $5000 \mathrm{~km}$ too and the values of $C_{0}=1480 \mathrm{~K}^{3 / 2} \mathrm{~s}^{-1}$ and $t_{0}=13: 39 \mathrm{UT}$ (19:00 LT in the northern hemisphere at geographic latitude $62.95^{\circ}$ and geographic longitude $80^{\circ}$ ) were selected for calculations of the additional heating rate given by Eq. (1).

Figures $1-3$ show the time variations of the modeled integral airglow intensities at $630 \mathrm{~nm}$ and the modeled

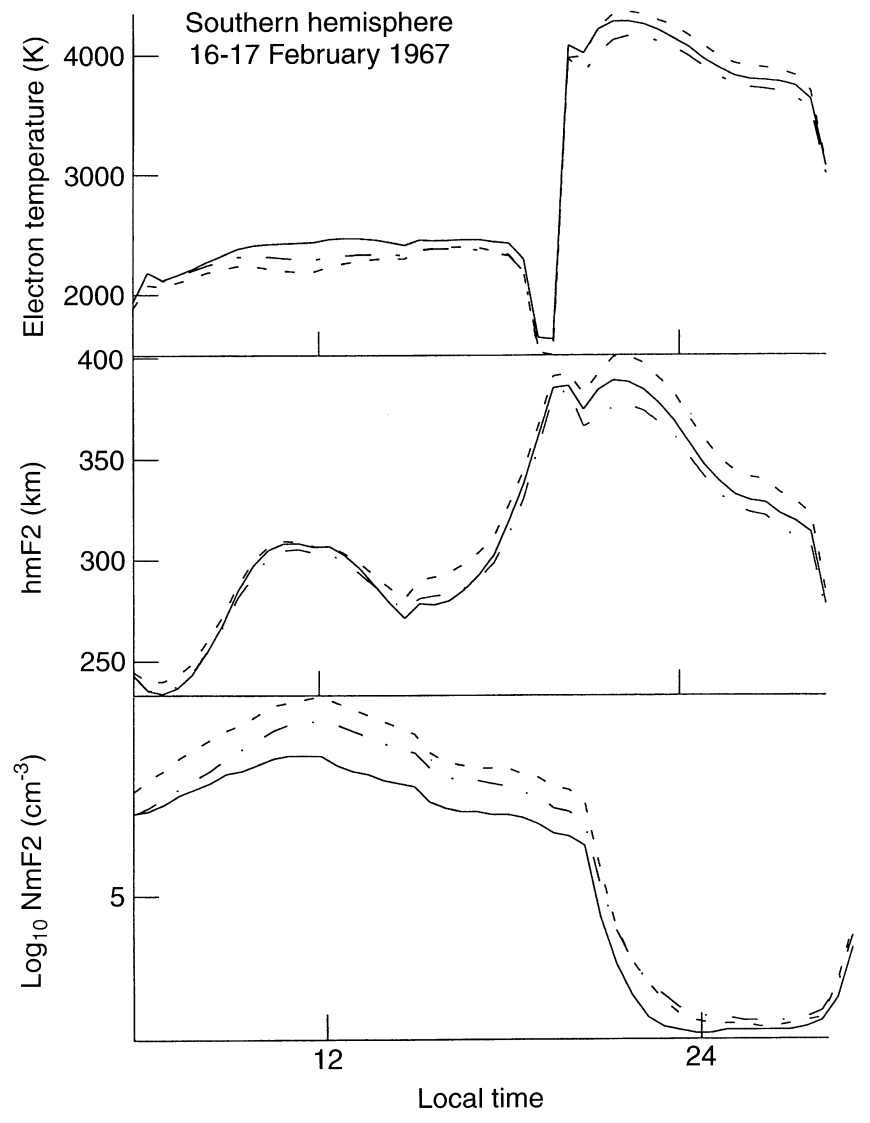

Fig. 2. The time variations of the modeled NmF2 (bottom panel), hmF2 (middle panel), and the electron temperature (top panel) at the $\mathrm{F} 2$ peak altitude in the SAR-arc region at $\mathrm{L}=2.72$ the southern hemisphere for the 16-17 February 1967 magnetic storm. The solid and dashed-dotted lines are $\mathrm{hmF} 2$ and $\mathrm{NmF} 2$ from the IZMIRAN model when the MSIS-86 atomic oxygen densities were decreased by a factor of 1.35 during the storm period in the southern hemisphere, and dashed lines are hmF2 and $\mathrm{NmF} 2$ with the original MSIS-86 atomic oxygen densities. The modeled results were obtained using the Boltzmann vibrational distribution of $\mathrm{N}_{2}(j)$ (dashed-dotted lines) and the non-Boltzmann populations of the first five vibrational levels by solving the $\mathrm{N}_{2}(j=1-5)$ time-dependent continuity and energy equations (A19, A20) (solid and dotted lines) and the model $\mathrm{A}$ of the rate coefficients of $\mathrm{O}^{+}\left({ }^{4} \mathrm{~S}\right)$ ions with the vibrationally excited nitrogen molecules and quenching of $\mathrm{O}^{+}\left({ }^{2} \mathrm{D}\right)$ by atomic oxygen

F2 peak parameters $\mathrm{NmF} 2, \mathrm{hmF} 2$, and $T_{e m}$ in the SAR arc regions at $\mathrm{L}=2.72$ in the northern and southern hemispheres for the 16-17 February 1967 magnetic storm which will be explained later. Crosses shown in Fig. 1 represent the integral intensities at $630 \mathrm{~nm}$ in the SAR-arc regions measured by the OV1-10 photometer at 21:47 LT (northern hemisphere) and 22:15 LT (southern hemisphere) on 16 February 1967.

The excitation of atomic oxygen by thermal electrons provides the main contribution to the values of the integral intensity at $630 \mathrm{~nm}$ in the SAR-arc region. The rate, $P_{t}$, of $\mathrm{O}\left({ }^{1} \mathrm{D}\right)$ formation in collision of atomic oxygen with thermal electrons determined by Eq. (A18) of the Appendix depends on $T_{c}$. Due to this dependence, the production of $\mathrm{O}\left({ }^{1} \mathrm{D}\right)$ increases with increasing $T_{e}$. However, as given by Eq. (A18), the production rate decreases linearly with decreasing electron density. A 


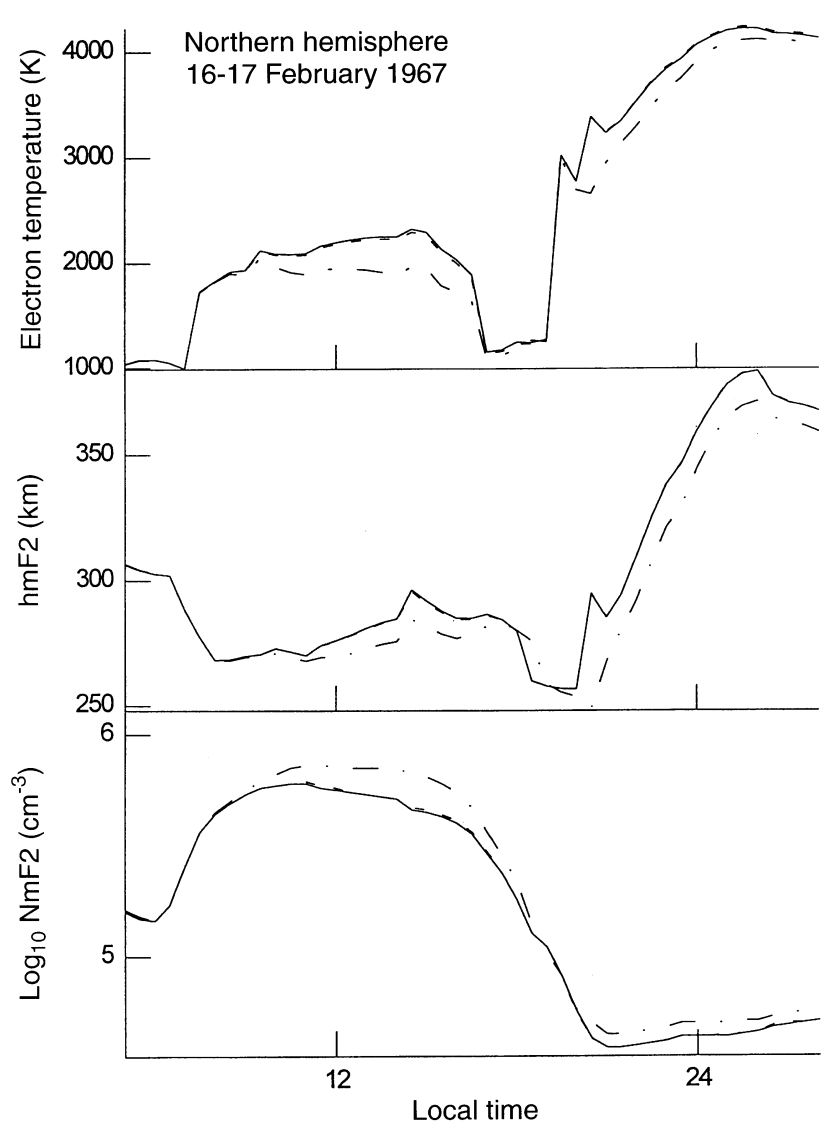

Fig. 3. The time variations of the modeled F2 peak parameters in the SAR-arc region at $\mathrm{L}=2.72$ the northern hemisphere for 15-17 February 1967 magnetic storm. Top: $T_{e}$. Middle: hmF2. Bottom: $\mathrm{NmF}$. The curves are the same as in Fig. 1 (the dashed lines are very close to the solid lines and are not seen in the Fig. 2)

decrease in $N_{e}$, causes an increase in $T_{e}$ (the electron-ion cooling rate of the thermal electrons is proportional to $N_{e}^{2}$ ) and an increase in $T_{e}$ causes an decrease in $N_{e}$ (as a result of the reactions of vibrationally excited nitrogen molecules $\mathrm{N}_{2}(j=1-5)$ with $\mathrm{O}^{+}\left({ }^{4} \mathrm{~S}\right)$ ions shown in Table 1 in the Appendix). Therefore, the resulting dependence of $P_{t}$ (and, hence, the volume emission rate, $V_{630}$, and $\left.I_{630}\right)$ on $N_{e}$ and $T_{e}$ appears to be very complex. The main causes of the variations of the integral intensity at 630 $\mathrm{nm}$ in the SAR-arc region are the variations in $N_{e}$ and $T_{e}$ in the region close to and above the $\mathrm{F} 2$ region, which are determined by the variations in the modeled F2 peak altitude, hmF2, and density, $\mathrm{NmF}$, and the modeled electron temperature, $T_{e m}$, at the F2 peak altitude.

\section{The role of non-Boltzmann distribution of vibrationally excited molecular nitrogen}

The vibrational distribution of $\mathrm{N}_{2}$ at levels does not follow a Boltzmann distribution in the $\mathrm{F}$ region of the ionosphere (Newton et al., 1974; Torr and Torr, 1982; Pavlov, 1988, 1989; Pavlov and Namgaladze, 1988; Pavlov and Buonsanto, 1997). These deviations can affect the recombination rate of $\mathrm{O}^{+}\left({ }^{4} \mathrm{~S}\right)$ ions and the

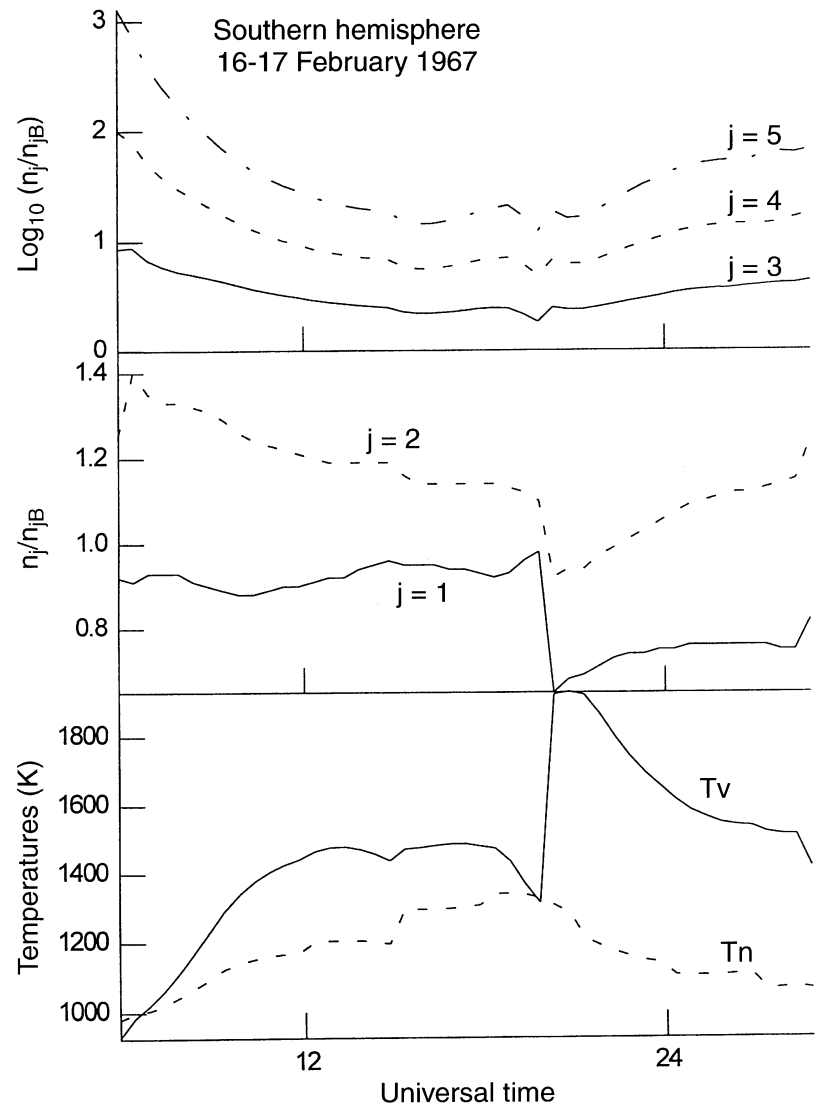

Fig. 4. The time variations of the vibrational and neutral temperatures and populations of the first five vibrational levels of $\mathrm{N}_{2}(j)$ in comparison with the Boltzmann distribution during the 15-17 February period at the F2 peak altitude within the SAR-arc regions at $\mathrm{L}=2.72$ in the northern hemisphere. The solid lines show the modeled $T_{y}, n_{1} / n_{1 B}$, and $n_{3} / n_{3 B}$, and the dashed lines show the modeled $T_{n}, n_{2} / n_{2 B}$ and $n_{4} / n_{4 B}$, and the dashed-dotted line is the modeled $n_{5} / n_{5 B}$. The model $\mathrm{A}$ of the rate coefficients of $\mathrm{O}^{+}\left({ }^{4} \mathrm{~S}\right)$ ions with the vibrationally excited nitrogen molecules and quenching of $\mathrm{O}^{+}\left({ }^{2} \mathrm{D}\right)$ by atomic oxygen was used in the IZMIRAN model

heating rate of electrons which influence the electron temperature and density and the integral airglow intensities at $630 \mathrm{~nm}$ in the SAR-arc regions.

The calculated fractional deviation of the $\mathrm{N}_{2}$ vibrational populations from a Boltzmann one, $n_{j} / n_{j B}$, the vibrational temperature, $T_{v}$ of $\mathrm{N}_{2}(j)$, and the neutral temperature, $T_{n}$, at the F2 peak altitude are presented in Fig. 4 (southern hemisphere) and Fig. 5 (northern hemisphere). The present study suggests that the calculated distribution is highly non-Boltzmann at vibrational levels $j>2$. The deviations from the Boltzmann distribution are not significant at the first and second vibrational levels of $\mathrm{N}_{2}$. Decreases in $n_{j} / n_{j B}$ and an increase in $T_{v}$ are seen at the recovery phase, after the beginning of the increase in $T_{e}$ due to the additional heating rate of electrons. Unlike the northern hemisphere, the nighttime minimum values of $n_{j} / n_{j B}$ ( $j=1-2)$ and the nighttime maximum value of $T_{v}$ are realized near $t_{0}$ at 20.19-20.49 LT on 16 February in the southern hemisphere. In the northern hemisphere the deviations $n_{j} / n_{j B}(j=2-5)$ and the vibrational temper- 


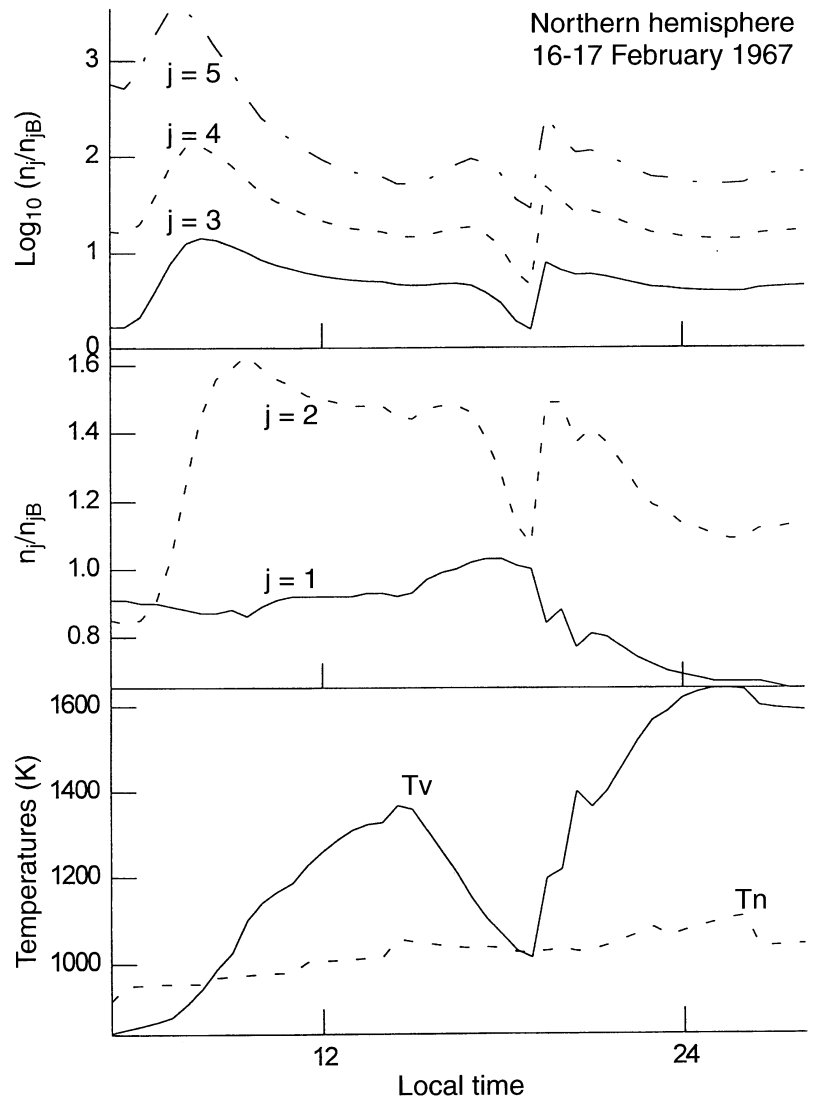

Fig. 5. The time variations of the vibrational and neutral temperatures and populations of the first five vibrational levels of $\mathrm{N}_{2}$ in comparison with the Boltzmann distribution during the 15-17 February period at the F2 peak altitude within the SAR-arc regions at $\mathrm{L}=2.72$ in the southern hemisphere. The curves are the same as in Fig. 4

ature have their minimum values at 19:00 LT on 16 February. From the diurnal variations of the calculated vibrational (solid line) and neutral (dashed line) temperatures shown in Figs. 4 and 5, it follows that $T_{v}<T_{n}$ in the atmosphere during the night without the additional heating rate of electrons where the production frequency of $\mathrm{N}_{2}(j)$ is low [details are given by Pavlov (1994)]. This means that for these periods the populations of $\mathrm{N}_{2}(j)$ are less than the populations for a Boltzmann distribution with temperature $T_{n}$. In the SAR-arc regions $T_{v}$ is larger than $T_{n}$ due to the enhanced thermal excitation of $\mathrm{N}_{2}$ as a result of high thermal electron temperatures at F2-region altitudes, but this difference between $T_{v}$ and $T_{n}$ is not more than $712 \mathrm{~K}$ in the either hemisphere.

The modeled results shown in Figs. 1-3 were obtained from the IZMIRAN model using the Boltzmann vibrational distribution of $\mathrm{N}_{2}(j)$ (dashed-dotted lines) by solving the time-dependent energy equation, Eq. (A20), for the vibrational quanta of $\mathrm{N}_{2}(j)$ and the nonBoltzmann populations of the first five vibrational levels of $\mathrm{N}_{2}(j)$ (solid and dotted lines) by solving the $\mathrm{N}_{2}(j=1-5)$ time-dependent continuity and energy equations, Eqs. (A19-A20).
Figure 1 shows that the use of the non-Boltzmann vibrational distribution of $\mathrm{N}_{2}$ and the choice of $C_{0}=1480 \mathrm{~K}^{3 / 2} \mathrm{~s}^{-1}$ in Eq. (1) brings the measured and modeled integral intensity at $630 \mathrm{~nm}$ into agreement only in the northern hemisphere. It seems likely that the intensity discrepancy between the measured and modeled $I_{630}$ of the southern hemisphere (the disagreement between the dotted lines and the cross at the top panel of Fig. 1) is caused by inaccuracies in key inputs such as the composition and temperature of the neutral atmosphere (the MSIS-86 model does not accurately predict the neutral atmosphere during a magnetic storm). We found that the integral intensity at $630 \mathrm{~nm}$ of the SAR arc region is much more sensitive to the variations in the oxygen number densities than the number densities of $\mathrm{N}_{2}, \mathrm{O}_{2}$ and the neutral temperature. Solid lines in Fig. 1 show the model results when the MSIS-86 neutral atomic oxygen density of the southern hemisphere was decreased by the factor of 1.35 at all altitudes during the geomagnetic storm period. No adjustments were made to the $[\mathrm{O}]$ values before a sudden storm commencement at 23:48 UT on 15 February. This MSIS- 86 correction is enough to reproduce very well the observed $I_{630}$ on 16 February.

It can be seen from the comparison between the solid line (marked 1) and the dashed-dotted lines of Fig. 1 and those of Figs. 2 and 3, that in the SAR-arc regions the non-Boltzmann distribution assumption leads to the decrease in the calculated $\mathrm{NmF} 2$ up to a factor of 1.2 1.4 and brings about reductions by factors of 1.1-1.2 in the integral intensity at $630 \mathrm{~nm}$ in comparison with $\mathrm{NmF} 2$ and the integral intensity calculated using the Boltzmann vibrational distribution of $\mathrm{N}_{2}$.

From our calculations it follows that the use of the Boltzmann vibrational distribution of $\mathrm{N}_{2}$ gives good agreement between measured and modeled $I_{630}$ of the northern hemisphere if we choose the value of $C_{0}=1450 \mathrm{~K}^{3 / 2} \mathrm{~s}^{-1}$ in Eq. (1). However, in order to reproduce the observed $I_{630}$ of the southern hemisphere it is necessary to decrease by a factor of 1.55 the MSIS86 neutral atomic oxygen density in the southern hemisphere at all altitudes during the geomagnetic storm period. Therefore, the use of the non-Boltzmann distribution assumption improves the agreement between the data and the theoretical results giving lower the ratio of the southern-hemisphere intensity to the northern-hemisphere intensity in comparison with the Boltzmann distribution assumption.

\section{Effects of the $O\left({ }^{1} D\right)$ diffusion and the uncertainities in the rate coefficients of $\mathrm{O}^{+}\left({ }^{4} \mathrm{~S}\right)$ and $\mathrm{O}^{+}\left({ }^{2} \mathrm{D}\right)$ ions on the integral intensity at $630 \mathrm{~nm}$}

We use one of the important changes of the IZMIRAN model given in the Appendix to take into account the effect of the $\mathrm{O}\left({ }^{1} \mathrm{D}\right)$ diffusion on the volume emission and the integral intensity at $630 \mathrm{~nm}$. To model these effects on $\left[\mathrm{O}^{1}(\mathrm{D})\right]$, the diffusion term in the $\mathrm{O}\left({ }^{1} \mathrm{D}\right)$ continuity Eq. (A24) of the IZMIRAN model was added.

Figure 6 shows calculated altitude profiles of volume emission rate at $630 \mathrm{~nm}$ for the 16 February 1971 


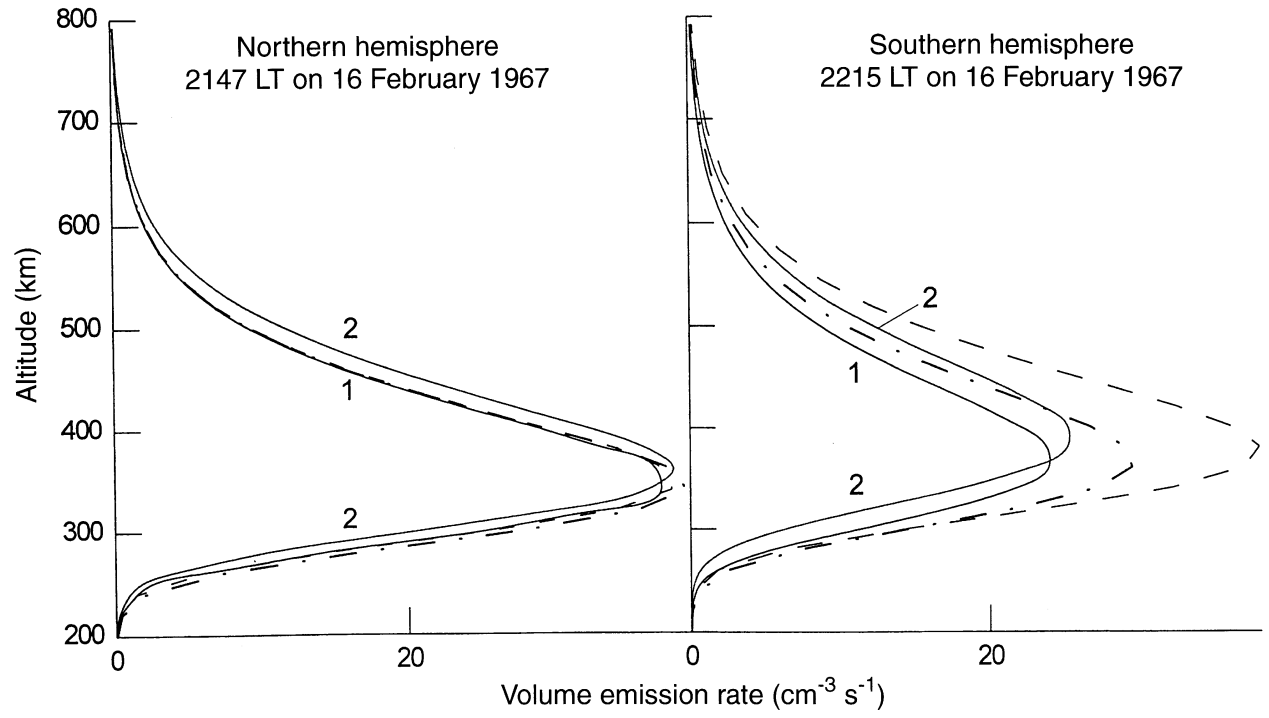

Fig. 6. Computed altitude profiles of volume emission rate at $630 \mathrm{~nm}$ for 16 February 1971 magnetic storm within the SAR arc regions at $\mathrm{L}=2.72$ in the northern (left panel) and southern (right panel) hemispheres at 2147 and 2215 LT. The curves are the same as in Fig. 1

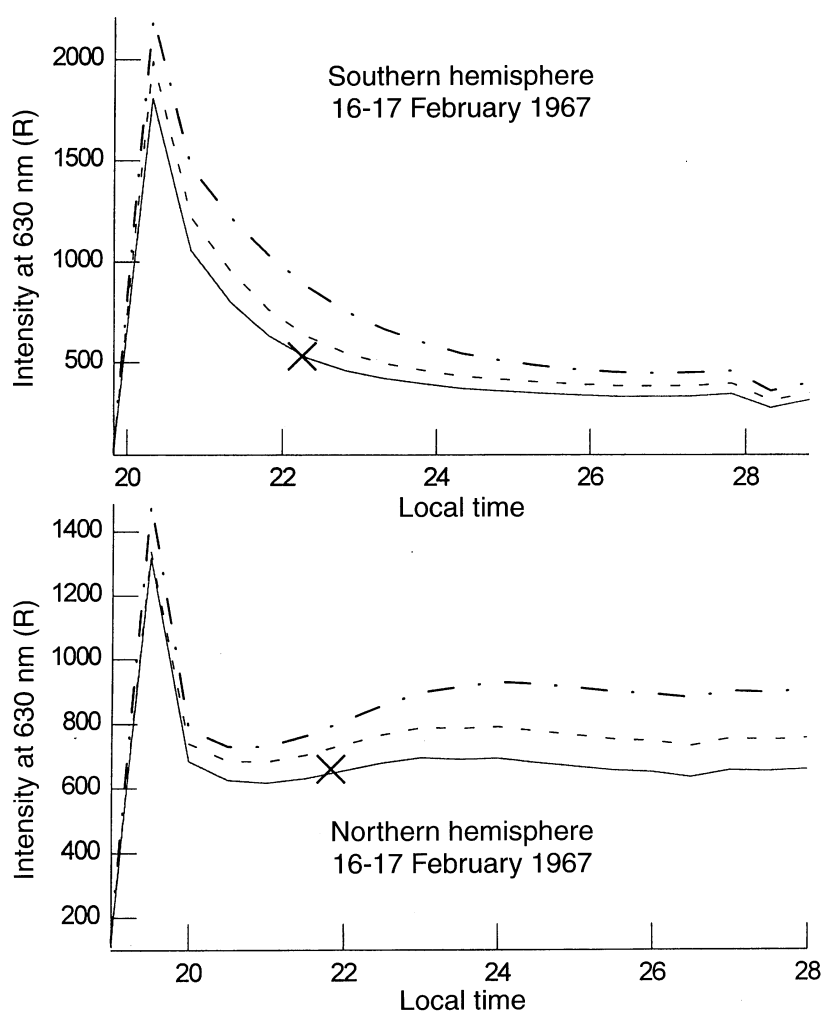

Fig. 7. The time variations of the modeled integral intensities at $630 \mathrm{~nm}$ in the SAR-arc regions in the northern (bottom panel) and southern (top panel) hemispheres at $\mathrm{L}=2.72$ for the recovery phase of the 16-17 February 1967 magnetic storm. Crosses represent the integral intensities at $630 \mathrm{~nm}$ in the SAR-arc regions measured by the OV1-10 photometer at 21:47 LT (northern hemisphere) and 22:15 LT (southern hemisphere) on 16 February 1967. The solid, dashed and dashed-dotted lines are the calculated integral intensities from model $\mathrm{A}, \mathrm{B}$, and $\mathrm{C}$ of the rate coefficients of $\mathrm{O}^{+}\left({ }^{4} \mathrm{~S}\right)$ ions with the vibrationally excited nitrogen molecules and quenching of $\mathrm{O}^{+}\left({ }^{2} \mathrm{D}\right)$ by atomic oxygen described in the Appendix. The modeled results were obtained using the non-Boltzmann populations of the first five vibrational levels by solving the $\mathrm{N}_{2}(j=1-5)$ time-dependent continuity equations A19, A20 when the diffusion of $\mathrm{O}\left({ }^{1} \mathrm{D}\right)$ was included in the IZMIRAN model and the MSIS- 86 atomic oxygen densities were decreased by the factor 1.35 during the storm period in the southern hemisphere magnetic storm within the SAR-arc regions at $\mathrm{L}=2.72$ in the northern (left panel) and southern (right panel) hemispheres at 21:47 LT and 22:15 LT on 16 February 1967 when the measurements of $I_{630}$ were made by the OV1-10 photometer. In Figs. 1 and 6 the solid lines marked by 1 show the results when we use in the IZMIRAN model the $\mathrm{O}\left({ }^{1} \mathrm{D}\right)$ continuity Eq. (A24) with the diffusion term, whereas the solid lines marked 2 were obtained without the diffusion of $\mathrm{O}\left({ }^{1} \mathrm{D}\right)$. It can been seen from the comparison of lines 1 and 2 that the effect of including the $\mathrm{O}\left({ }^{1} \mathrm{D}\right)$ diffusion results in a decrease of $4-6 \%$ in the calculated integral intensity of the northern hemisphere and of $7-13 \%$ in the calculated integral intensity of the southern hemisphere. These changes in the integral intensities are caused by volume emission rate changes. Figure 6 shows that the effect of using the $\mathrm{O}\left({ }^{1} \mathrm{D}\right)$ diffusion in the IZMIRAN model results in a 20 $26-\mathrm{km}$ decrease in the modeled peak altitude of the volume emission rate.

The updated IZMIRAN model includes the option to use models A, B, or $\mathrm{C}$ of the rate coefficients of $\mathrm{O}^{+}\left({ }^{4} \mathrm{~S}\right)$ ions with the vibrationally excited nitrogen molecules and quenching of $\mathrm{O}^{+}\left({ }^{3} \mathrm{D}\right)$ by atomic oxygen described in the Appendix. The results shown in Figs. 1-6 were obtained using model A. Figure 7 shows the time variations of the modeled integral airglow intensities at $630 \mathrm{~nm}$ from models A (solid lines), B (dashed lines), and $\mathrm{C}$ (dashed-dotted lines) in the SAR-arc regions at $\mathrm{L}=2.72$ in the northern (bottom panel) and southern (top panel) hemispheres for the 16-17 February 1967 magnetic storm. Crosses shown in Fig. 7 represent the integral intensities at $630 \mathrm{~nm}$ in the SAR-arc regions measured by the OVI-10 photometer. The used values of $C_{0}, t_{0}$, and $s_{0}$ in Eq. (1) were the same as for results shown in Figs. 1-6 and the MSIS-86 neutral atomic oxygen density of the southern hemisphere was decreased by the factor of 1.35 in models $\mathrm{A}, \mathrm{B}$, and $\mathrm{C}$ at all altitudes during the geomagnetic storm period.

The modeled $N_{e}, T_{e}$, and $I_{630}$ are sensitive to the assumed values of the rate coefficients of $\mathrm{O}^{+}\left({ }^{4} \mathrm{~S}\right)$ ions with the vibrationally excited nitrogen molecules and 
quenching of $\mathrm{O}^{+}\left({ }^{2} \mathrm{D}\right)$ by atomic oxygen. The modeled $N_{e}$ are larger in model $\mathrm{B}$ than in model $\mathrm{A}$, and in model $\mathrm{C}$ than in model $\mathrm{B}$ in the SAR-arc regions (at altitudes close and above the $\mathrm{F} 2$ region). As a result, the modeled $I_{630}$ increases in the SAR-arc regions by $1-15 \%$ (northern hemisphere) and 10-21\% (southern hemisphere) in model $\mathrm{B}$, and by a factor 1.1-1.4 (northern hemisphere) and 1.2-1.65 (southern hemisphere) in model $\mathrm{C}$, in comparison with model A.

\section{Conclusions}

This paper presented a comparison between measured and calculated integral airglow intensities at $630 \mathrm{~nm}$ in the SAR-arc regions of the northern and southern hemispheres, corresponding to the time-period of the 15-17 February 1967 magnetic storm. The model used is an enhanced and updated version of the IZMIRAN model that has been steadily developed over the years. This time-dependent mathematical model of the Earth's ionosphere and plasmasphere includes interhemispheric coupling, the $\mathrm{H}^{+}, \mathrm{O}^{+}\left({ }^{4} \mathrm{~S}\right), \mathrm{He}^{+}, \mathrm{O}^{+}\left({ }^{2} \mathrm{D}\right), \mathrm{O}^{+}\left({ }^{2} \mathrm{P}\right), \mathrm{NO}^{+}$, $\mathrm{O}_{2}^{+}$, and $\mathrm{N}_{2}^{+}$ions, electrons, photoelectrons, the electron and ion temperatures, vibrationally excited nitrogen molecules, the components of thermospheric wind, $\mathrm{O}\left({ }^{1} \mathrm{D}\right)$ atoms and the MSIS-86 neutral atmosphere model. The major enhancements to the IZMIRAN model added for this study are the inclusion of the $\mathrm{He}^{+}$ ions (three major ions: $\mathrm{O}^{+}, \mathrm{H}^{+}$, and $\mathrm{He}^{+}$and three ion temperature), the updated photochemistry and energy balance equations for ions and electrons, the diffusion of $\mathrm{NO}^{+}$and $\mathrm{O}_{2}^{+}$ions and $\mathrm{O}\left({ }^{1} \mathrm{D}\right)$ and the revised electron cooling rates arising from their collisions with unexcited $\mathrm{N}_{2}, \mathrm{O}_{2}$ molecules and $\mathrm{N}_{2}$ molecules at the the first vibrational level. The updated model includes the option to use the models of the Boltzmann or non-Boltzmann distributions of vibrationally excited molecular nitrogen. In order to model the electron temperature, the additional heating rate of the electron gas providing the heat flux to the SAR-arc region was added in the energy balance equation at the altitude above $5000 \mathrm{~km}$ during the recovery phase of the geomagnetic storm.

The deviations from the Boltzmann distribution for the first five vibrational levels of $\mathrm{N}_{2}$ were calculated. The present study suggests that the calculated distribution is highly non-Boltzmann at the vibrational levels $j>2$ and the deviations from the Boltzmann distribution are not significant at the first and second vibrational levels of $\mathrm{N}_{2}$. It was found that the non-Boltzmann distribution assumption leads to the decrease in the calculated $\mathrm{NmF} 2$ up to a factor of 1.2-1.4 and brings about factors of 1.11.2 reductions in the integral intensity at $630 \mathrm{~nm}$ in comparison with $\mathrm{NmF} 2$ and the integral intensity calculated using the Boltzmann vibrational distribution of $\mathrm{N}_{2}$. The MSIS-86 oxygen number densities of the southern hemisphere were decreased by a factor of 1.35 at all altitudes for the storm period 15-17 February in order to decrease the modeled integral intensity to match observations better. The preceding results indicate that the use of the non-Boltzmann distribution assumption improves the agreement between the data and the theoretical results decreasing the ratio of the calculated southern-hemisphere intensity to the northern-hemisphere intensity.

The enhanced IZMIRAN model used for this study takes into account the effect of the $\mathrm{O}\left({ }^{1} \mathrm{D}\right)$ diffusion on the volume emission and the integral intensity at $630 \mathrm{~nm}$. We found that in the SAR-arc region the inclusion $\mathrm{O}\left({ }^{1} \mathrm{D}\right)$ diffusion results in a $20-26-\mathrm{km}$ decrease in the modeled peak altitude of volume emission rate, in a decrease of $4-6 \%$ in the calculated integral intensity of the northern hemisphere and $7-13 \%$ in the calculated integral intensity of the southern hemisphere. The modeled intensities of the southern hemisphere are more sensitive to the assumed values of the rate coefficients of $\mathrm{O}^{+}\left({ }^{4} \mathrm{~S}\right)$ ions with the vibrationally excited nitrogen molecules and quenching of $\mathrm{O}^{+}\left({ }^{2} \mathrm{D}\right)$ by atomic oxygen than the modeled intensities of the northern hemisphere.

Acknowledgements. The research described in this publication was supported by grant 96-05-64031 from the Russian Foundation of the Fundamental Researches.

Topical Editor D. Alcaydé thanks A. Nagy and D. Slaver for their help in evaluating this paper.

\section{Appendix IZMIRAN model description}

The model used is an enhanced and updated version of one that we have steadily developed over the years (Pavlov, 1991, 1994, 1996; Pavlov and Buonsanto, 1997). In the model, coupled time-dependent equations of continuity, momentum, and energy balance for $\mathrm{O}^{+}\left({ }^{4} \mathrm{~S}\right), \mathrm{H}^{+}$, and $\mathrm{He}^{+}$ions, and electrons are solved along a centered-dipole magnetic field line for the concentrations, field-aligned diffusion velocities, and temperatures of ions and electrons from a base altitude $(160 \mathrm{~km})$ in the northern hemisphere through the plasmasphere to the same base altitude in the southern hemisphere. In the northern and southern hemispheres the model solves time-dependent continuity equations for $\mathrm{O}^{+}\left({ }^{2} \mathrm{D}\right), \mathrm{O}^{+}\left({ }^{2} \mathrm{P}\right), \mathrm{NO}^{+}, \mathrm{O}_{2}^{+}, \mathrm{N}_{2}^{+}$, vibrationally excited molecular nitrogen, $\mathrm{N}_{2}(v)$, at the first five vibrational levels $v=1-5$, and the momentum equations for the horizontal components of thermospheric wind within the altitude range 120-700 $\mathrm{km}$ and the time-dependent continuity equation for $\mathrm{O}\left({ }^{1} \mathrm{D}\right)$ in the region between 120 and $1500 \mathrm{~km}$ in altitude.

\section{Ion continuity equations}

The ion continuity equations for the three major ions, $\mathrm{O}^{+}\left({ }^{4} \mathrm{~S}\right), \mathrm{H}^{+}$, and $\mathrm{He}^{+}$and for the minor ions, $\mathrm{O}^{+}\left({ }^{2} \mathrm{D}\right), \mathrm{O}^{+}\left({ }^{2} \mathrm{P}\right), \mathrm{NO}^{+}, \mathrm{O}_{2}^{+}$, and $\mathrm{N}_{2}^{+}$are given by

$\frac{\partial}{\partial t} N_{j}+B \frac{\partial}{\partial s} C_{i} N_{j} B^{-1}=Q_{j}+\Delta Q_{j}+P_{j}-L_{j}$,

where $N_{j}$ is the ion concentration, $B$ is the geomagnetic field, $t$ is the local time, $s$ is the distance along the magnetic field line, positive in the direction north to south, $P_{j}$ and $L_{j}$ are the production rates and the ion loss rates by the chemical reactions of Table $1, Q_{j}$ and $\Delta Q_{j}$ are the 
Table 1. Chemistry of ions ( ${ }^{\text {a }}$ The effective temperature $T=\left(m_{i} T_{n}+m_{n} T_{i}\right) /\left(m_{i}+m_{n}\right)+m_{i} m_{n} V_{d}^{2}\left[3 k\left(m_{i}+m_{n}\right)\right]^{-1}$ where $V_{d}$ is plasma drift velocity)

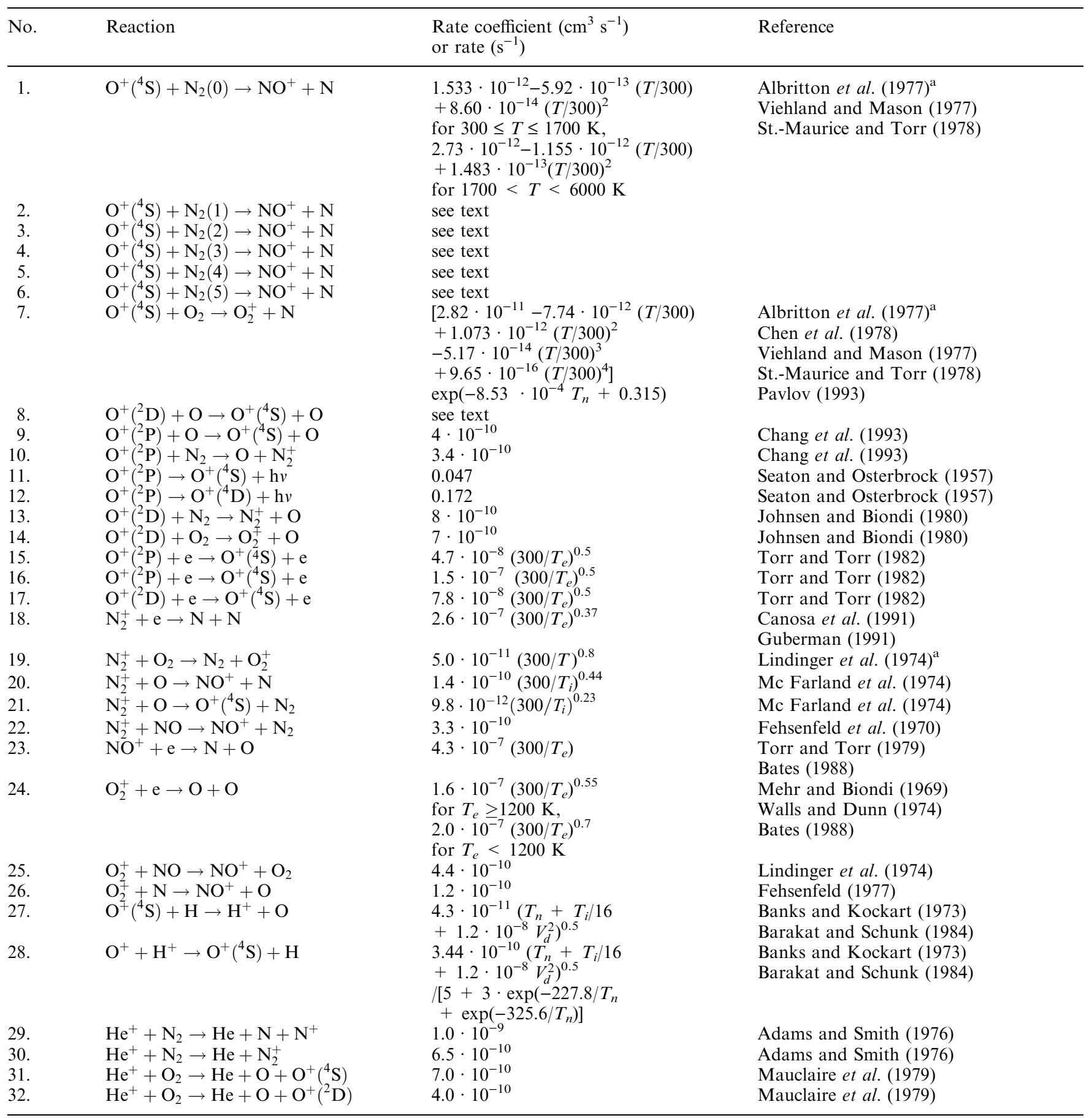

production rates of ions by photoionization and due to photoelectrons, $C_{j}=V_{j}+W, V_{j}$ is the field-aligned diffusion velocity, $W$ is the field-aligned wind-induced plasma drift velocity. In our model we neglect the $C_{j}$ effects on the $\mathrm{O}^{+}\left({ }^{2} \mathrm{D}\right), \mathrm{O}^{+}\left({ }^{2} \mathrm{P}\right)$, and $\mathrm{N}_{2}^{+}$ion concentrations.

In the present model, the solar EUV fluxes, $\Phi_{\propto}(\lambda)$, are obtained from the EUVAC model (Richards et al., 1994) or EUV94X model (Tobiska, 1993, 1994). The reactions of photoionization and the ionization due to photoelectrons of the neutral species, $\mathrm{N}_{2}, \mathrm{O}_{2}, \mathrm{O}$, and $\mathrm{He}$ are included in the model. We use Eqs. (A3) and (A5) in Pavlov (1994) to calculate $Q_{j}$ and $\Delta Q_{j}$. The revised photoionization and photoabsorption cross sections are taken from Richards et al. (1994); these authors did not publish the photoionization cross section for $\mathrm{He}$, and for these we have used values from Torr and Torr (1982). The Chapman function approximation is taken from Smith and Smith (1972). The model results are sensitive in the key rate coefficients $K_{2}-K_{6}$, and $K_{8}$ of the reactions 2-6 and 8 presented in Table 1. 
The recombination rate coefficients of $\mathrm{O}^{+}\left({ }^{4} \mathrm{~S}\right)$ ions with $\mathrm{N}_{2}(v>0)$ were measured by Schmeltekopf et al. (1968) and Ferguson et al. (1984) for $T_{n}=T_{i}=300 \mathrm{~K}$. Van Zandt and O'Malley (1973) determined the dependence of these rate coefficients on the neutral temperature by using the results of Schmeltekopf et al. (1968) and a simple theoretical model of these reactions. Pavlov (1988) enlarged the use of this approach by taking into account the dependence of these rate coefficients on the effective temperature, and changed the rate coefficient of $\mathrm{O}^{+}\left({ }^{4} \mathrm{~S}\right)$ ions with $\mathrm{N}_{2}(0)$ given by Van Zandt and O'Malley (1973) to the rate coefficient $K_{1}$ of Table 1.

The rate coefficient for the quenching of $\mathrm{O}^{+}\left({ }^{2} \mathrm{D}\right)$ by atomic oxygen has not been measured and was assumed to be $10^{-10} \mathrm{~cm}^{3} \mathrm{~s}^{-1}$ (Oppenheimer et al., 1977; Fox and Dalgarno, 1985) and $5 \cdot 10^{-12} \mathrm{~cm}^{3} \mathrm{~s}^{-1}$ (Abdou et al., 1984). These rate coefficients were obtained from agreement between the measured and model densities of $\mathrm{N}_{2}^{+}$ and the different points of view were discussed by Torr and Torr (1982), Abdou et al. (1984), Ferguson (1984), and Fox and Dalgarno (1985).

Our model of the thermal plasma in the ionosphere and plasmasphere includes the option to use three sets for models of these rate coefficients. In model A the rate coefficient $K_{\mathrm{s}}=10^{-10} \mathrm{~cm}^{3} \mathrm{~s}^{-1}$ and the rate coefficients $K_{2}-K_{6}$ are determined by the equations given by Pavlov (1988) and Pavlov and Namgaladze (1988). This approach was used in the IZMIRAN model (Pavlov, 1994, 1996; Pavlov and Buonsanto, 1997). Model B uses $K_{8}=5.10^{-12} \mathrm{~cm}^{3} \mathrm{~s}^{-1}$ and the recombination rate coefficients of $\mathrm{O}^{+}\left({ }^{4} \mathrm{~S}\right)$ ions with $\mathrm{N}_{2}(v>0)$ measured by Schmeltekopf et al. (1968) for $T_{n}=T_{i}=300 \mathrm{~K}: K_{2}=$ $1.3 \cdot 10^{-12} \mathrm{~cm}^{3} \mathrm{~s}^{-1}, \quad K_{3}=5.0 \cdot 10^{-11} \mathrm{~cm}^{3} \mathrm{~s}^{-1}, \quad K_{4}=1.2$. $10^{-10} \mathrm{~cm}^{3} \mathrm{~s}^{-1}, K_{5}=2.6 \cdot 10^{-10} \mathrm{~cm}^{3} \mathrm{~s}^{-1}, K_{6}=3.6 \cdot 10^{-10}$ $\mathrm{cm}^{3} \mathrm{~s}^{-1}$. In model $\mathrm{C}$ the rate coefficient $K_{8}=5.0$. $10^{-12} \mathrm{~cm}^{3} \mathrm{~s}^{-1}$ and the ratios of the recombination rate coefficients of $\mathrm{O}^{+}\left({ }^{4} \mathrm{~S}\right)$ ions with $\mathrm{N}_{2}(v>0)$ to the rate coefficients of $\mathrm{O}^{+}\left({ }^{4} \mathrm{~S}\right)$ ions with $\mathrm{N}_{2}(0)$ are the same as measured by Schmeltekopf et al. (1968) for $T_{n}=T_{i}=300 K: K_{2}(T) / K_{1}(T)=1, K_{3}(T) / K_{1}(T)=38$, $K_{4}(T) / K_{1}(T)=85, K_{5}(T) / K_{1}(T)=220, K_{6}(T) / K_{1}(T)=$ 270 . The model $\mathrm{C}$ assumes that the temperature dependence of these reactions rates are the same as for unexcited $\mathrm{N}_{2}$, i.e., are as given by St. Maurice and Torr (1978). This approach was used in the FILP model (Torr et al., 1990)

\section{Transport formulation}

The momentum equations for determination of the ion field-aligned velocities were formulated by Conrad and Schunk (1979). In updated "low-speed" model the nonlinear acceleration terms and stress tensor divergences are neglected and the ion diffusion velocities are calculated by solving the system equations

$$
\begin{aligned}
& \sum_{j} v_{i j}\left(1-\Delta_{i j}\right)\left(V_{j}-V_{i}\right)-V_{i} \sum_{n} v_{i n}\left(1-\Delta_{i n}\right) \\
& =\left[\frac{\partial}{\partial s} p_{i}+N_{i} N_{e}^{-1} \frac{\partial}{\partial s} P_{e}+m_{i} N_{i} g+p_{i} \gamma_{i} \frac{\partial}{\partial s} \ln T_{i}\right]\left(m_{i} N_{i}\right)^{-1},
\end{aligned}
$$

where $N_{e}$ is the electron concentration, $p_{e}=k N_{e} T_{e}$, $P_{i}=k N_{i} T_{i}, k$ is Boltzmann's coefficient, $T_{e}$ is the electron temperature, $T_{i}$ is the $i$-th ion temperature, $m_{i}$ denotes the mass of the ith ion, $v_{i j}$ and $v_{i n}$ are the collision frequencies for momentum transfer between ions and between ion and neutral, the thermal diffusion coefficients $\gamma_{i}$ and the correction factors $\Delta_{i j}$ and $\Delta_{i n}$ are given by Conrad and Schunk (1979), $g=\sin I$ $\left(g_{0} L^{-2} \sin ^{-4} \theta-1.5 \Omega^{2} L \mathrm{R}_{\mathrm{E}} \sin ^{4} \theta\right), L=r \mathrm{R}_{\mathrm{E}}^{-1} \sin ^{-2} \theta$ is the McIlwain parameter, $\Omega=7.3 \cdot 10^{-5} \mathrm{~s}^{-1}, g_{0}=980$ $\mathrm{cm} \mathrm{s}^{-2}, r$ denotes radial distance from the Earth's center, $\theta$ is the geomagnetic colatitude, $I$ is the magnetic field dip angle, $\sin I=2 \cos \theta\left(1+3 \cos ^{2} \theta\right)^{-0.5}$.

The wind-induced plasma drift velocity

$W_{d}=U_{\theta} \cos I$,

where $U_{\theta}$ is the component of thermospheric wind in spherical polar coordinates $(r, \theta, \phi), \phi$ is the geomagnetic longitude.

For determination of the value of $U_{\theta}$ it is necessary to solve the system of momentum Eqs. (A13, A14) given by Pavlov (1994). The large uncertainities in the calculated $U_{\theta}$ lead to large errors in the modeled electron densities and peak height altitude, hmF2, of the F2-layer (Richards, 1991; Pavlov, 1994). This problem was largely overcome when Richards (1991) developed a technique for deriving equivalent neutral winds from the observed hmF2. Ideally, the observed $\mathrm{hmF} 2$ should be available for several hours before the time of the comparison, but very often only a limited set of hmF2 measurements is available or we have not got the observed hmF2 and thus cannot use the method developed by Richards (1991) or our modification of this method (Pavlov and Buonsanto, 1997) to calculate an equivalent plasma drift velocity. To overcome this problem, we can try to use hmF2 IRI given by the IRI-90 model (Bilitza, 1990) to calculate an equivalent plasma drift velocity, $W_{\text {IRI }}$, for some hypothetical undisturbed conditions with the same solar and time conditions as during the studied conditions:

$$
\begin{gathered}
W_{\mathrm{IRI}}(t+\Delta t)=\left[h m F 2_{\mathrm{IRI}}(t+\Delta t)\right. \\
-\operatorname{hmF} 2(t)] \beta(t)^{-1}+W_{\mathrm{IRI}}(t), \\
\beta(t)=1.76 \cdot 10^{-5}\left[T_{n}\left(T_{i}+T_{e}\right)^{-1}+0.46\right] \\
\left(T_{n} v_{i n}\right)^{2 / 3} L\left(\mathrm{O}^{+}\right)^{-1 / 3},
\end{gathered}
$$

where $h m F 2(t)$ and $W_{\mathrm{IRI}}(t)$ are the calculated heights of the F2 layer and the equivalent drift velocity of the plasma at time $t, L\left(\mathrm{O}^{+}\right)$is the recombination rate of the $\mathrm{O}^{+}\left({ }^{4} \mathrm{~S}\right)$ ions, the values of $T_{n}, T_{e}, T_{i}, v_{i n}$, and $L\left(\mathrm{O}^{+}\right)$are given at $300-\mathrm{km}$ altitude (the dependence of $\beta$ on altitude is small at the F-region altitudes because of $\left.\beta(t) \sim\left\{[\mathrm{O}]^{2} L^{-1}\right\}^{1 / 3}\right)$.

After that we calculate the wind-induced plasma drift velocities

$W_{q}=U_{\theta}$ (quiet) $\cos I, W_{m}=U_{\theta}$ (modeled) $\cos I$, 
where $U_{\theta}$ (quiet) and $U_{\theta}$ (modeled) are the horizontal components of the thermospheric wind for hypothetical quiet and real studied conditions obtained by solving the two momentum Eqs. (A13, A14) of Pavlov (1994) for these conditions.

Finally, in the northern and southern hemispheres the plasma drift velocities in the ion continuity equations are given by Pavlov (1996) as

$W_{d}=W_{m}-W_{q}+W_{\mathrm{IRI}}$.

Such an approach allows us to avoid some serious errors in the calculations of electron density during magnetic storms (Pavlov and Buonsanto, 1997). During quiet conditions the modeled hmF2 are very close to hmF2 IRI.

If we have the observed peak height altitude, $h m F 2_{\text {exp }}$, of the F2-layer in the northern or southern hemispheres then the algorithm developed by Richards (1991) with our modification (Pavlov and Buonsanto, 1997) is used to calculate $W_{d}$ for this hemisphere

$W_{d}(t+\Delta t)=\left[\mathrm{hmF} 2_{\exp }(t+\Delta t)-\mathrm{hmF}(t)\right] \beta(t)^{-1}+W_{d}(t)$,

where $\operatorname{hmf}(t)$ and $W_{d}(t)$ are the calculated heights of the $\mathrm{F} 2$ layer and the equivalent drift velocity of the plasma at time $t, \beta(t)$ is determined by Eq. (A5).

\section{Energy balance equations for ions and electrons}

The energy balance equations for ions and electrons

$$
\begin{aligned}
1.5 \frac{\partial}{\partial t} T_{i} & =B\left(k N_{i}\right)^{-1} \frac{\partial}{\partial s} \lambda_{i} B^{-1} \frac{\partial}{\partial s} T_{i}-T_{i} B \frac{\partial}{\partial s} C_{i} B^{-1} \\
& -1.5 C_{i} \frac{\partial}{\partial s} T_{i}+v_{i e}\left(T_{e}-T_{i}\right) \\
& +3 m_{i}\left\{\sum_{j} v_{i j}\left(m_{i}+m_{j}\right)^{-1}\left(T_{j}-T_{i}\right)\right. \\
& \left.+\left(T_{n}-T_{i}\right) \sum_{n} v_{i n}\left(m_{i}+m_{n}\right)^{-1}\right\} \\
& +m_{i} k^{-1} V_{d}^{2} \sum_{n} v_{i n} m_{n}\left(m_{i}+m_{n}\right)^{-1} \\
1.5 k N_{e} \frac{\partial}{\partial t} T_{e} & =B \frac{\partial}{\partial s} \lambda_{e} B^{-1} \frac{\partial}{\partial s} T_{e} \\
& +P_{e}+P_{r c}-\sum_{l} L_{e l},
\end{aligned}
$$

where $V_{d}^{2}=W^{2}+\left(c E_{\perp} B^{-1}\right)^{2}\left\{1+\omega_{i}^{-2}\left(\sum v_{i n}\right)^{2}\right\}^{-1}, \omega_{i}$ is the ion cyclotron frequency, $E_{\perp}$ is the perpendicular component of the electric field with respect to the geomagnetic field, $c$ is the speed of light, $\lambda_{i}$ and $\lambda_{e}$ are the thermal conductivities of ions and electrons, $L_{e l}$ is the electron cooling rate in the process " $l$ ", $P_{e}$ is the heating rate of the electron gas by photoelectrons; to calculate $P_{e}(s)$ along a centered-dipole magnetic field line the numerical method of Krinberg and Tachilin (1984) for the determination of the photoelectron fluxes within a plasmaspheric field tube was used on the same field line grid that is used in solving for the densities and temperatures; $P_{r c}$ is the additional heating rate of the electron gas due to Coulomb collisions between ringcurrent ions and plasmaspheric electrons and waveelectron interactions.

To calculate the electron thermal conductivity coefficient we use the new mixture rule given by Pavlov (1996). The expressions used for $\lambda_{i}, v_{e i}, v_{i j}$, and $L_{e l}$ are given by Bailey and Sellec (1990). For the electron cooling rate, $L_{e l}\left(\mathrm{~N}_{2}^{*}\right)$, arising from their collisions with $\mathrm{N}_{2}$ molecules, with the excitation of vibrational levels $v=1-5$ of $\mathrm{N}_{2}(0)$ and $v=2-5$ of $\mathrm{N}_{2}(1)$, and the $\mathrm{N}_{2}^{*}$ deexcitation effect, the revised expression was used

$$
\begin{aligned}
& L_{e l}\left(\mathrm{~N}_{2}^{*}\right)=E_{1} \sum_{v=1}^{5} v I_{0 v}\left\{\left[\mathrm{~N}_{2}(0)\right]-\left[\mathrm{N}_{2}(v)\right] \exp \left(v E_{1} T_{e}^{-1}\right)\right\} \\
& +E_{1} \sum_{v=2}^{5}(v-1) I_{1 v}\left\{\left[\mathrm{~N}_{2}(1)\right]-\left[\mathrm{N}_{2}(v)\right] \exp \left((v-1) E_{1} T_{e}^{-1}\right)\right\},
\end{aligned}
$$

where

$I_{0 v}=N_{e}\left\{8 k T_{e}\left(\pi m_{e}\right)^{-1}\right\}^{0.5} \int_{0}^{\infty} \sigma_{0 v}(x) x \exp (-x) \mathrm{d} x$,

$$
I_{1 v}=N_{e}\left\{8 k T_{e}\left(\pi m_{e}\right)^{-1}\right\}^{0.5} \int_{0}^{\infty} \sigma_{1 v}(x) x \exp (-x) \mathrm{d} x,
$$

and where $x=E\left(k T_{e}\right)^{-1}, E$ is electron energy $E_{1}=3353 \mathrm{~K}$ is the energy of the first level of $\mathrm{N}_{2}$ given by Radzig and Smirnov (1980), $\sigma_{0 v}(E)$ are the partial cross sections for excitation of $\mathrm{N}_{2}(0)$ by electrons, $\sigma_{1 v}(E)$ are the partial cross sections for excitation of $\mathrm{N}_{2}(\mathrm{l})$ by electrons.

The results presented in this paper were obtained using $\sigma_{01}(E)$ complied by Itikawa et al. (1986) for the region of electron energy from 0.3 to $1.8 \mathrm{eV}$. We used $\sigma_{0 v}(E)$ recommended by Schulz (1976) for $E>1.8 \mathrm{eV}$ with the normalization factor of 0.7 given by Haddad (1984) and the absolute value of $\sigma_{01}(E)=4.45 \cdot 10^{-16}$ $\mathrm{cm}^{2}$ at $E=2 \mathrm{eV}$. The partial cross sections for excitation of $\mathrm{N}_{2}(1)$ to $\mathrm{N}_{2}(v>1)$ by electrons calculated by Dube and Herzenberg (1979) for $v=2-4$ were adjusted to give the best fit of the calculated $\sigma_{01}(E)$ also from Dube and Herzenberg (1979), to the measured $\sigma_{01}(E)$. The values of $\sigma_{1 v}(E)$ calculated by Chen (1964) for $v=5$ were modified by taking into account the new values of $\sigma_{0 v}(E)$.

For the electron cooling rate, $L_{e 1}\left(\mathrm{O}_{2}^{*}\right)$, arising from collisions of electrons with unexcited $\mathrm{O}_{2}$ molecules with the excitation of vibrational levels $v=1-4$ of $\mathrm{O}_{2}(0)$ and the $\mathrm{O}_{2}^{*}$ de-excitation effect revised expression was used

$$
L_{e l}\left(\mathrm{O}_{2}^{*}\right)=E_{1}^{\prime} N_{e} \sum_{v=1}^{4} v J_{v}\left\{\left[\mathrm{O}_{2}(0)\right]-\left[\mathrm{O}_{2}(v)\right] \exp \left(v E_{1}^{\prime} T_{e}^{-1}\right)\right\},
$$


Table 2. Coefficients for calculations of the electron cooling rate due to $\mathrm{O}_{2}^{*}$

\begin{tabular}{lcrrrrrrrrrrrrr}
\hline$j$ & 1 & \multicolumn{1}{c}{2} & \multicolumn{1}{c}{3} & \multicolumn{1}{c}{4} & \multicolumn{1}{c}{5} & \multicolumn{1}{c}{6} & 7 & 8 & 9 & 10 & 11 & 12 & 13 \\
\hline$E_{j}^{*}$ & 3829 & 5222 & 6603 & 7961 & 9295 & 10610 & 11895 & 13171 & 14413 & 15620 & 16815 & 17987 & 19136 \\
$S_{j 1}$ & 95.7 & 428 & 726 & 796 & 567 & 371 & 202 & 119 & 72.1 & 0 & 0 & 0 & 0 \\
$S_{j 2}$ & 0 & 0 & 112 & 398 & 595 & 594 & 452 & 316 & 167 & 75.0 & 33.6 & 0 & 0 \\
$S_{j 3}$ & 0 & 0 & 0 & 0 & 36.3 & 175 & 261 & 277 & 251 & 155 & 90.8 & 54.0 & 0 \\
$S_{j 4}$ & 0 & 0 & 0 & 0 & 0 & 0 & 0 & 52.6 & 110 & 125 & 114 & 71.9 & 76.5 \\
\hline
\end{tabular}

where $J_{v}=\left\{8 k T_{e}\left(\pi m_{e}\right)^{-1}\right\}^{0.5} \int_{0}^{\infty} \Omega_{0 v}(x) x \exp (-x) \mathrm{d} x$, $x=E\left(k T_{e}\right)^{-1}, E$ is an energy of electrons, $E_{1}^{\prime}=2239 \mathrm{~K}$ is the energy of the first level of $\mathrm{O}_{2}$ given by Radzig and Smirnov (1980), $\Omega_{0 v}(E)$ are partial cross sections for excitation of $\mathrm{O}_{2}(0)$ by electron impact.

The vibrational-excitation cross sections of $\mathrm{O}_{2}(0)$, as a function of impact energy, exhibit very sharp and narrow spikes (Schulz, 1976). The use of the measured integral vibrational-excitation cross sections in these narrow spikes given by Schulz (1976) leads to the new electron cooling rate due to $\mathrm{O}_{2}^{*}$ :

$$
\begin{gathered}
L_{e l}\left(\mathrm{O}_{2}^{*}\right)=1.61 \cdot 10^{-4} N_{e} T_{e}^{-1.5} \sum_{v=1}^{4}\left\{\left[\mathrm{O}_{2}(0)\right]-\left[\mathrm{O}_{2}(v)\right]\right. \\
\left.\exp \left(v E_{1}^{\prime} T_{e}^{-1}\right)\right\} \sum_{j=1}^{13} S_{j v} \exp \left(-E_{j}^{*} T_{e}^{-1}\right),
\end{gathered}
$$

where the values of $S_{j v}$ and $E_{j}^{*}$ are given in Table 2, the units of $\left[\mathrm{O}_{2}(0)\right],\left[\mathrm{O}_{2}(v)\right]$ and $N_{e}$ are $\mathrm{cm}^{-3}$, the units of $T_{e}$ are $\mathrm{K}$, the units of $L_{e l}\left(\mathrm{O}_{2}^{*}\right)$ are $\mathrm{K} \mathrm{cm}^{-3} \mathrm{~s}^{-1}$.

To calculate the number densities of $\mathrm{O}_{2}(v)$ we use a Boltzmann distribution with the vibrational temperature $T_{v}\left(\mathrm{O}_{2}^{*}\right)=T_{n}$

$\left[\mathrm{O}_{2}(v)\right]=\left[\mathrm{O}_{2}(0)\right] \exp \left(-v E_{1}^{\prime} T_{n}^{-1}\right)$

From Eq. (A16) it may similarly be shown that the sum of the vibrationally unexcited and excited molecular oxygen concentrations $\quad\left[\mathrm{O}_{2}\right]=\left[\mathrm{O}_{2}(0)\right]\{1-\exp$ $\left.\left(-E_{1}^{\prime} T_{n}^{-1}\right)\right\}$. There is no possibility to differentiate the vibrationally unexcited $\mathrm{O}_{2}$ from the vibrationally excited $\mathrm{O}_{2}$ during the mass-spectrometer measurements of the neutral species in the atmosphere, and we therefore believe that the MSIS-86 neutral model (Hedin, 1987) used in our model calculates the value of $\left[\mathrm{O}_{2}\right]$. The difference between $\left[\mathrm{O}_{2}\right]$ and $\left[\mathrm{O}_{2}(0)\right]$ is not negligible during solar maximum. For example $\left[\mathrm{O}_{2}\right] /\left[\mathrm{O}_{2}(0)\right]$ $=1.29$ for $T_{n}=1500 \mathrm{~K}$.

We use the revised cooling rate in collision of $\mathrm{O}\left({ }^{3} \mathrm{P}\right)$ with thermal electrons

$L_{e l}\left(\mathrm{O}\left({ }^{1} \mathrm{D}\right)\right)=E_{0} P_{t}$,

where the rate of $\mathrm{O}\left({ }^{1} \mathrm{D}\right)$ formation in collision of $\mathrm{O}\left({ }^{3} \mathrm{P}\right)$ with thermal electrons is calculated as (Pavlov, 1990, 1996)

$$
\begin{aligned}
& P_{t}=C N_{e}\left\{[\mathrm{O}]-1.8\left[\mathrm{O}\left({ }^{1} \mathrm{D}\right)\right] \exp (X)\right\} X^{0.5} \\
& \quad\left(1+a_{1} X-a_{2} X^{2}\right)\left(b_{1}+b_{2} X+X^{2}\right)^{-1} \exp (-X),
\end{aligned}
$$

$X=E_{0} T_{e}^{-1}, E_{0}=22861 \mathrm{~K} ; C=2.72 \cdot 10^{-8} \mathrm{~cm}^{3} \mathrm{~s}^{-1}, a_{1}=$ $7.8035 \cdot 10^{-2}, \quad a_{2}=3.4534 \cdot 10^{-3}, \quad b_{1}=1.6882, b_{2}=$
3.331, the units of [O], $\left[\mathrm{O}\left({ }^{1} \mathrm{D}\right)\right]$, and $N_{e}$ are $\mathrm{cm}^{-3}$, the units of $T_{e}$ are $\mathrm{K}$, the units of $L_{e l}\left(\mathrm{O}\left({ }^{1} \mathrm{D}\right)\right)$ are $\mathrm{K}$ $\mathrm{cm}^{-3} \mathrm{~s}^{-1}$.

The loss rate of the $\mathrm{O}^{+}\left({ }^{4} \mathrm{~S}\right)$ ions and $L_{e l}\left(\mathrm{~N}_{2}^{*}\right)$ are functions of number densities, $n_{j}$, of vibrationally excited molecular nitrogen $\mathrm{N}_{2}(j)$. The model includes the option to use the models of the Boltzmann and nonBoltzmann distributions of vibrationally excited molecular nitrogen.

Continuity and energy equations for the vibrationally excited nitrogen molecules

Pavlov $(1988,1989)$ treated the vibrationally excited nitrogen molecules as a set of harmonic and anharmonic oscillator energy levels. The Pavlov (1989) study suggests that the effect of anharmonicity on $n_{j}$ is small at the energy levels $j=1-5$. Therefore our model uses the system of equations given by Pavlov (1988) and Pavlov and Namgaladze (1988) to determine $n_{j}(j=1-5)$ using the harmonic oscillator energy level approximation, the vibrational-vibrational and vibrational-translational energy exchange of $\mathrm{N}_{2}(j)$, the diffusion of $\mathrm{N}_{2}(j)$ in the mixture of $\mathrm{N}_{2}(0), \mathrm{O}_{2}$, and $\mathrm{O}$, the production rates, $\mathrm{Q}_{j}$, of $\mathrm{N}_{2}(j)$ as follows:

$$
\begin{aligned}
& \frac{\partial}{\partial t} n_{j}+\frac{\partial}{\partial z} F_{j}\left(\mathrm{~N}_{2}^{*}\right)=\left\{(j+1) n_{j+1}-[(j+1) \Theta+j] n_{j}\right. \\
&\left.+j \Theta n_{j-1}\right\} \tau_{v t}^{-1}+\left\{(j+1)(1+\alpha) n_{j+1}\right. \\
&\left.-[(j+1) \alpha+j(1+\alpha)] n_{j}+j \alpha n_{j-1}\right\} \tau_{v v}^{-1}+Q_{j}, \\
& \frac{\partial}{\partial t} \alpha-\frac{1}{n} \frac{\partial}{\partial z} D n \frac{\partial}{\partial z} \alpha=\frac{1}{n} \sum_{j} j Q_{j}-\left(\alpha-\frac{\Theta}{1-\Theta}\right) \tau_{v t}^{-1} \\
&-\alpha K_{m}\left[\mathrm{CO}_{2}\right],
\end{aligned}
$$

where $F_{j}\left(\mathrm{~N}_{2}^{*}\right)=-D\left[\frac{\partial}{\partial z} n_{j}+n_{j}\left(\frac{1}{H}+\frac{1}{T_{n}} \frac{\partial}{\partial z} T_{n}\right)\right], n=\sum_{j} n_{j}, \alpha$ $=\frac{1}{n} \sum_{j} j n_{j}, \Theta=\exp \left(-E_{1} T_{n}^{-1}\right), \tau_{v t}^{-1}=\left\{K_{v t}^{(1)}[\mathrm{O}]+K_{v t}^{(2)}\left[\mathrm{O}_{2}\right]\right\}$ $(1-\Theta), \tau_{v v}^{-1}=K_{v v} n, H=k T_{n}(\mathrm{mg})^{-1}, D$ is the diffusion coefficient of the vibrationally excited nitrogen molecules, $m$ denotes the mass of $\mathrm{N}_{2}, \mathrm{~g}$ is the acceleration due to gravity, $E_{1}=3353 \mathrm{~K}$, the rate coefficients of the vibrational-translational energy exchange $\mathrm{N}_{2}(j=1)-\mathrm{O}$ is measured by McNeal et al. (1974) and can be approximated as $K_{v t}^{(1)}=1.07 \cdot 10^{-10} \exp \left(-69.9 T_{n}^{-1 / 3}\right)$ $\mathrm{cm}^{3} \mathrm{~s}^{-1}$ by use of the theory of this energy exchange, the rate coefficients of the vibrational-translational energy 
exchange $\mathrm{N}_{2}(j=1)-\mathrm{O}_{2}$ is given by Gilmore et al. (1969) as $K_{v t}^{(2)}=3.6 \cdot 10^{-12} T_{n}^{0.5} \exp \left(-110 T_{n}^{-1 / 3}\right) \mathrm{cm}^{3} \mathrm{~s}^{-1}$, for the vibrational-vibrational energy exchange of $N_{2}(j=1)$ with $\mathrm{CO}_{2}$ Taylor (1974) presented $K_{m}=1.7 \cdot 10^{-6}$ $\exp \left(-175 T_{n}^{-1 / 3}\right)+6.2 \cdot 10^{-14} \exp \left(-15.13 T_{n}^{-1 / 3}\right) \mathrm{cm}^{3}$ $\mathrm{s}^{-1}$, the rate coefficients of the vibrational-vibrational energy exchange of $\mathrm{N}_{2}(j=1)$ with $N_{2}(j=0)$ is measured by Suchkov and Schebeko (1981) as $K_{v v}=5.2 \cdot 10^{-10} T_{n}^{-3 / 2} \mathrm{~cm}^{3} \mathrm{~s}^{-1}$.

It is required to know the value of $n_{6}$ to calculate the value of $n_{5}$ from Eqs. (A19, A20), and the condition $n_{6}=0$ was assumed. The diffusion coefficients of vibrationally excited molecules are not sensitive to the number of energy level (Fujimoto et al., 1976) and we can use

$$
\begin{aligned}
D & =Y\left\{[\mathrm{O}]\left(D\left(\mathrm{~N}_{2}, \mathrm{O}\right)\right)^{-1}+\left[\mathrm{N}_{2}\right]\left(D\left(\mathrm{~N}_{2}, \mathrm{~N}_{2}\right)\right)^{-1}\right. \\
& \left.+\left[\mathrm{O}_{2}\right]\left(D\left(\mathrm{~N}_{2}, \mathrm{O}_{2}\right)\right)^{-1}\right\}^{-1}
\end{aligned}
$$

where $Y=[\mathrm{O}]+\left[\mathrm{N}_{2}\right]+\left[\mathrm{O}_{2}\right]$, the binary diffusion coefficients of the unexcited $\mathrm{N}_{2}$ molecules (Pavlov, 1981; Pavlov and Namgaladze, 1988) $D\left(\mathrm{~N}_{2}, \mathrm{O}\right)=9.69 \cdot 10^{16}$ $\cdot T_{n}^{0.774} Y^{-1}, D\left(\mathrm{~N}_{2}, \mathrm{~N}_{2}\right)=9.76 \cdot 10^{16} \cdot T_{n}^{0.69} \quad Y^{-1}, D\left(\mathrm{~N}_{2}\right.$, $\left.\mathrm{O}_{2}\right)=8.29 \cdot 10^{16} \cdot T_{n}^{0.724} Y^{-1}$, the units of $[\mathrm{O}],\left[\mathrm{O}_{2}\right]$ and $\left[\mathrm{N}_{2}\right]$ are $\mathrm{cm}^{-3}$ and the units of $D$ are $\mathrm{cm}^{-3} \mathrm{~s}^{-1}$.

The production rates of $\mathrm{N}_{2}(j)$ are given as

$$
\begin{aligned}
Q_{j} & =I_{0 j}\left\{n_{0}-n_{j} \exp \left(j E_{1} T_{e}^{-1}\right)\right\} \\
& +I_{1 j}\left\{n_{1}-n_{j} \exp \left[(j-1) E_{1} T_{e}^{-1}\right]\right\}+Q_{j 1}+Q_{j 2},
\end{aligned}
$$

where the first two terms describe the thermal electron excitation of $\mathrm{N}_{2}(0)$ and $\mathrm{N}_{2}(1)$ and the deexcitation of $\mathrm{N}_{2}(j)$, the values of $I_{0 j}$ and $I_{1 j}$ are determined by Eqs. (A12 and A13), $\mathrm{Q}_{j 1}$ and $\mathrm{Q}_{j 2}$ are the $\mathrm{N}_{2}(j)$ production rates in the reactions $\mathrm{O}\left({ }^{1} \mathrm{D}\right)$ with $\mathrm{N}_{2}(0)$ and $\mathrm{N}\left({ }^{4} \mathrm{~S}\right)$ with $\mathrm{NO}$.

The rate coefficients, $\gamma_{j}$, of the reactions $\mathrm{O}\left({ }^{1} \mathrm{D}\right)$ $+\mathrm{N}_{2}(0) \rightarrow \mathrm{O}+\mathrm{N}_{2}(j)$ are not measured. Streit et al. (1976) reported that the measured rate coefficient $\gamma=\sum_{j} \gamma_{j}$. Tully (1974) developed a classic collision complex model to describe production of $\mathrm{N}_{2}(j)$ in these reactions. This theoretical approach defines $\gamma=\int_{0}^{E^{*}}$ $K(E) d E$, where $E^{*}$ is the critical energy of the potential surface intersection of $\mathrm{N}_{2} \mathrm{O}$ with separated $\mathrm{O}\left({ }^{3} \mathrm{P}\right)$ $+\mathrm{N}_{2}, K(E)$ is a partial rate constat for formation of $\mathrm{N}_{2}(j)$ vibrational energy between $E$ and $E+d E$ calculated by Tully (1974) for $E^{*}=1.18$ and $1.97 \mathrm{eV}$.

The predicted value of $\gamma$ given by Tully (1974) agrees with the experimental results of Streit et al. (1976). Although there is considerable uncertainty in the theoretical results, they suggest that the amount of energy channeled into $\mathrm{N}_{2}$ vibration can be an average of $30 \pm$ $10 \%$ of the $1.97-\mathrm{eV}$ exothermicity of quenching. This is in excellent agreement with the measurements of Slanger and Black (1974) who concluded that an average of $33 \pm$ $10 \%$ of the $1.97-\mathrm{eV}$ electronic energy of $\mathrm{O}\left({ }^{1} \mathrm{D}\right)$ converts into $\mathrm{N}_{2}$ vibrational energy.

Using $K(E)$ we calculate the branching ratios as $\frac{\gamma_{j}}{\gamma}=\int_{E_{j-1}}^{E_{j}} \mathrm{~K}(\mathrm{E}) \mathrm{dE}\left(\int_{0}^{E *} \mathrm{~K}(\mathrm{E}) \mathrm{dE}\right)^{-1}$, where $E_{j}$ is the energy of the $j$-th vibrational level of $\mathrm{N}_{2}(j)$. Our model use the values of $\frac{\gamma_{j}}{\gamma}=0.293,0.253,0.212,0.159,0.083$ for $j=1-5$ and $\frac{\gamma_{j}}{\gamma}=0$ for $j>5$, the measured rate coeffi- cient $\gamma$ given by Streit et al. (1976) and the production rate of $\mathrm{N}_{2}(j)$ in the reaction $\mathrm{O}\left({ }^{1} \mathrm{D}\right)$, with $\mathrm{N}_{2}(0)$ as $Q_{j 1}=\gamma_{j}\left[\mathrm{O}\left({ }^{1} \mathrm{D}\right] n_{0}\right.$. For these values of $\frac{\gamma_{j}}{\gamma}$ an average of $36 \%$ of the $1.97-\mathrm{eV}$ electronic energy of $\mathrm{O}\left({ }^{1} \mathrm{D}\right)$ converts into $\mathrm{N}_{2}$ vibrational energy, in excellent agreement with the measurements of Slanger and Black (1974).

The vibrationally excited nitrogen molecules may be also produced in the reactions $\mathrm{N}\left({ }^{4} \mathrm{~S}\right)$ with $\mathrm{NO}$ with the rate $Q_{j 2}=\varepsilon_{j} \beta\left[\mathrm{N}\left({ }^{4} \mathrm{~S}\right)\right][\mathrm{NO}]$, where $\beta=3.4 \cdot 10^{-11} \mathrm{~cm}^{3} \mathrm{~s}^{-1}$ (Lee et al., 1978 ), $\varepsilon_{j}$ is the probability vibrational distribution given by Phillips and Schiff (1962).

Solving the system Eqs. (A19), (A20) the model can calculate the number densities of vibrational excited molecular nitrogen determining the real non-Boltzmann distribution of $\mathrm{N}_{2}(j)$. The model includes the option to use the model of the Boltzmann distributions of vibrationally excited molecular nitrogen

$n_{j}=n_{j B}=n_{0 B}\left[\alpha(1+\alpha)^{-1}\right]^{j}=n_{0 B} \exp \left(-j E_{1} T_{v}^{-1}\right)$,

where $T_{v}$ is the vibrational temperature and the value of $\alpha$ is calculated from Eq. (A20). In this case from Eq. (A23) it may be similarly be shown that the sum of the vibrationally unexcited and excited molecular nitrogen concentrations $\left[\mathrm{N}_{2}\right]=n=n_{0 B}(1+\alpha)$. There is no possibility to differentiate the vibrationally unexcited $\mathrm{N}_{2}$ from the vibrationally excited $\mathrm{N}_{2}$ during the massspectrometer measurements of the neutral species in the atmosphere, and therefore we believe that the MSIS-86 model calculates the value of $\left[\mathrm{N}_{2}\right]$. The difference between $\left[\mathrm{N}_{2}\right.$ ] and $n_{0 B}$ is not negligible during solar maximum conditions. For example $\left[\mathrm{N}_{2}\right] / n_{0 B}=1.12$ for $T_{v}=1500 \mathrm{~K}$.

\section{Continuity equation for $O\left({ }^{1} D\right)$}

We calculate $\left[\mathrm{O}\left({ }^{1} \mathrm{D}\right)\right]$ from the continuity equation using the chemical reactions of formation and loss of $\mathrm{O}\left({ }^{1} \mathrm{D}\right)$ presented in Table 3, the production of $\mathrm{O}\left({ }^{1} \mathrm{D}\right)$ in the photodissociation reaction of oxygen molecules, the $\mathrm{O}\left({ }^{1} \mathrm{D}\right)$ formation in collision of $\mathrm{O}\left({ }^{3} \mathrm{P}\right)$ with thermal electrons and photoelectrons, and the diffusion of $\mathrm{O}\left({ }^{1} \mathrm{D}\right)$ in the mixture of $\mathrm{N}_{2}(0), \mathrm{O}_{2}$, and $\mathrm{O}$ :

$$
\begin{aligned}
\frac{\partial}{\partial t}\left[\mathrm{O}\left({ }^{1} \mathrm{D}\right)\right]+\frac{\partial}{\partial z} F\left(\mathrm{O}\left({ }^{1} \mathrm{D}\right)\right) & =Q_{d}+P_{p h}+P_{t}+K_{1}\left[\mathrm{O}_{2}^{+}\right] N_{e} \\
& -\left\{K_{2}\left[\mathrm{~N}_{2}\right]+K_{3}\left[\mathrm{O}_{2}\right]+K_{4}[\mathrm{O}]\right. \\
& \left.+K_{5}+K_{6}+K_{7}\right\}\left[\mathrm{O}\left({ }^{1} \mathrm{D}\right)\right],
\end{aligned}
$$

where $\quad F\left(\mathrm{O}\left({ }^{1} \mathrm{D}\right)\right)=-D\left(\mathrm{O}\left({ }^{1} \mathrm{D}\right)\right)\left[\frac{\partial}{\partial z}\left[\mathrm{O}\left({ }^{1} \mathrm{D}\right)\right]+\left[\mathrm{O}\left({ }^{1} \mathrm{D}\right)\right]\right.$ $\left.\left(\frac{1}{H}+\frac{1}{T_{n}} \frac{\partial}{\partial z} T_{n}\right)\right], \quad Q_{d}=\left[\mathrm{O}_{2}\right] \sum_{\lambda} \sigma_{d}(\lambda) \Phi_{\propto}(\lambda) \quad \exp [-\tau(\lambda)]$, $H=k T_{n}(\mathrm{mg})^{-1}, \quad \mathrm{D}$ is the diffusion coefficient of $\mathrm{O}\left({ }^{1} \mathrm{D}\right), m$ denotes the mass of $\mathrm{O}, \tau(\lambda)$ is the optical depth at wavelength $\lambda, \sigma_{d}(\lambda)$ is the generally accepted photodissociation cross section of $\mathrm{O}_{2}$ with the production of $\mathrm{O}\left({ }^{1} \mathrm{D}\right)$ (Solomon et al., 1988), $P_{t}$ is determined by Eq. (A.18), $P_{p h}$ is the rate of the $\mathrm{O}\left({ }^{1} \mathrm{D}\right)$ formation in 
Table 3. The chemical processes of formation and loss of $\mathrm{O}\left({ }^{1} \mathrm{D}\right)$

\begin{tabular}{llll}
\hline No. & Reaction & $\begin{array}{l}\text { Rate coefficient }\left(\mathrm{cm}^{3} \mathrm{~s}^{-1}\right) \\
\text { or rate }\left(\mathrm{s}^{-1}\right)\end{array}$ & Reference \\
\hline 1. & $\mathrm{O}_{2}^{+}+\mathrm{e} \rightarrow \mathrm{O}\left({ }^{1} \mathrm{D}\right)+\mathrm{O}$ & $\begin{array}{l}1.76 \cdot 10^{-7}\left(300 / T_{e}\right)^{0.55} \\
\text { for } T_{e} \geq 1200 \mathrm{~K},\end{array}$ & $\begin{array}{l}\text { Mehr and Biondi (1969) } \\
\text { Walls and Dunn (1974) }\end{array}$ \\
& & $2.2 \cdot 10^{-7}\left(300 / T_{e}\right)^{0.7}$ & Bates (1988) \\
& & for $T_{e}<1200 \mathrm{~K}$ & Solomon et al. (1988) \\
2. & $\mathrm{O}\left({ }^{1} \mathrm{D}\right)+\mathrm{N}_{2} \rightarrow \mathrm{N}_{2}^{*}+\mathrm{O}$ & $2 \cdot 10^{-11} \exp \left(107.8 T_{n}^{-1}\right)$ & Streit et al. $(1976)$ \\
3. & $\mathrm{O}\left({ }^{1} \mathrm{D}\right)+\mathrm{O}_{2} \rightarrow \mathrm{O}{ }_{2}^{*}+\mathrm{O}$ & $3.2 \cdot 10^{-11} \exp \left(67 T_{n}^{-1}\right)$ & Streit et al. $(1976)$ \\
4. & $\mathrm{O}\left({ }^{1} \mathrm{D}\right)+\mathrm{O} \rightarrow \mathrm{O}+\mathrm{O}$ & $2.5 \cdot 10^{-12}$ & Sobral et al. $(1993)$ \\
5. & $\mathrm{O}\left({ }^{1} \mathrm{D}\right) \rightarrow \mathrm{O}\left({ }^{3} \mathrm{P}_{2}\right)+\mathrm{h} v$ & $5.63 \cdot 10^{-3}$ & Solomon et al. $(1988)$ \\
6. & $\mathrm{O}\left({ }^{1} \mathrm{D}\right) \rightarrow \mathrm{O}\left({ }^{3} \mathrm{P}_{1}\right)+\mathrm{h} v$ & $1.82 \cdot 10^{-3}$ & Solomon et al. $(1988)$ \\
7. & $\mathrm{O}\left({ }^{1} \mathrm{D}\right) \rightarrow \mathrm{O}\left({ }^{3} \mathrm{P}_{0}\right)+\mathrm{h} v$ & $8.92 \cdot 10^{-7}$ & Solomon et al. $(1988)$ \\
\hline
\end{tabular}

collision of $\mathrm{O}\left({ }^{3} \mathrm{P}\right)$ with photoelectrons, the value of $P_{p h}$ is calculated by using the semi-empirical formula (Pavlov, 1990; Konikov and Pavlov, 1991), $K_{i}(i=1-6)$ are the rate coefficients of the chemical reactions of Table 3.

We believe that the diffusion coefficient of $\mathrm{O}\left({ }^{1} \mathrm{D}\right)$ is the same as the diffusion coefficient of $\mathrm{O}\left({ }^{3} \mathrm{P}\right)$ in the mixture of $\mathrm{N}_{2}, \mathrm{O}_{2}$, and $\mathrm{O}\left({ }^{3} \mathrm{P}\right)$ :

$$
\begin{aligned}
D & =Y\left\{[\mathrm{O}](\mathrm{D}(\mathrm{O}, \mathrm{O}))^{-1}+\left[\mathrm{N}_{2}\right]\left(\mathrm{D}\left(\mathrm{O}, \mathrm{N}_{2}\right)\right)^{-1}\right. \\
& \left.+\left[\mathrm{O}_{2}\right]\left(\mathrm{D}\left(\mathrm{O}, \mathrm{O}_{2}\right)\right)^{-1}\right\}^{-1},
\end{aligned}
$$

where $Y=[\mathrm{O}]+\left[\mathrm{N}_{2}\right]+\left[\mathrm{O}_{2}\right]$, the binary diffusion coefficients (Pavlov, 1981), $D\left(\mathrm{O}, \mathrm{N}_{2}\right)=D\left(\mathrm{O}, \mathrm{O}_{2}\right)=9.69$. $10^{16} \cdot T_{n}^{0.774} Y^{-1}$, the self-diffusion coefficient of $\mathrm{O}$ is the function of the oxygen viscosity coefficient (Ferziger and Kaper, 1972) and can be calculated as $D(\mathrm{O}, \mathrm{O})=$ $1.94 \cdot 10^{17} \cdot T_{n}^{0.69} Y^{-1}$, the units of $[\mathrm{O}],\left[\mathrm{O}_{2}\right]$ and $\left[\mathrm{N}_{2}\right]$ are $\mathrm{cm}^{-3}$ and the units of $D$ are $\mathrm{cm}^{2} \mathrm{~s}^{-1}$.

Important characteristics of airglow that are calculated by the model are the volume emission rate at $630 \mathrm{~nm}$ and the integral intensity:

$\mathrm{V}_{630}=K_{5}\left[\mathrm{O}\left({ }^{1} \mathrm{D}\right)\right], \mathrm{I}_{630}=\int_{0}^{\infty} \mathrm{V}_{630}(z) \mathrm{d} z$.

\section{Model inputs}

The inputs for the model are a neutral atmosphere, the solar EUV fluxes, the perpendicular electric fields, and the additional heating rate of the electron gas due to Coulomb collisions between ring-current ions and plasmaspheric electrons and wave-electron interactions. The solar EUV fluxes are obtained from the EUVAC model (Richards et al., 1994) or EUV94X model (Tobiska, 1993, 1994). To specify the neutral temperature and the number densities of $\mathrm{N}_{2}, \mathrm{O}_{2}, \mathrm{O}$, and $\mathrm{N}$ we utilize the MSIS-86 model (Hedin, 1987) using the 3-h $A_{p}$ index as an indicator of the geomagnetic activity. To calculate the density of NO the same scheme of the processes of formation and loss of NO as in Iwagami and Ogawa (1987) is used, so it is not presented here: The ratio of $\left[\mathrm{CO}_{2}\right]$ to $\left(\left[\mathrm{O}_{2}\right]+\left[\mathrm{N}_{2}\right]+[\mathrm{O}]\right)$ can be taken as $3 \cdot 10^{-4}$ at $120 \mathrm{~km}$ (Banks and Kockarts, 1973). Above $120 \mathrm{~km}$ the model uses $\left[\mathrm{CO}_{2}\right](z)=\left[\mathrm{CO}_{2}\right]\left(z_{0}\right)$ $\exp \left\{-\left(z-z_{0}\right) H^{-1}\right\}$, where $z_{0}=120 \mathrm{~km}, H=k T_{n}(\mathrm{mg})^{-1}$, $m$ denotes the mass of $\mathrm{CO}_{2}$.

\section{Lower and upper boundary conditions}

The lower boundary $160 \mathrm{~km}$ is set for determination of $\left[\mathrm{O}^{+}\left({ }^{4} \mathrm{~S}\right)\right],\left[\mathrm{H}^{+}\right],\left[\mathrm{He}^{+}\right]$, field-aligned diffusion velocities, and temperatures of ions and electrons from Eqs. (A1, A2, A9, A10) in the northern and southern hemispheres. At this base altitude the diffusion processes of $\mathrm{O}^{+}\left({ }^{4} \mathrm{~S}\right), \mathrm{H}^{+}, \mathrm{He}^{+}$ions and the processes of transfer of thermal energy of electrons and ions were neglected. At the lower boundary $(120 \mathrm{~km})$ the viscosity terms in the momentum equations, the diffusion processes of $\mathrm{O}_{2}^{+}$and $\mathrm{NO}^{+}$ions, $\mathrm{O}\left({ }^{1} \mathrm{D}\right)$, vibrationally excited molecules and vibrational quanta are neglected in the northern and southern hemispheres. The upper boundary conditions are assumed as $V_{i}=0$ for $\mathrm{O}_{2}^{+}$and $\mathrm{NO}^{+}$ions (see Eq. A2), $\frac{\partial}{\partial z} \alpha=0, F_{j}\left(\mathrm{~N}_{2}^{*}\right)=0, \frac{\partial}{\partial r} U_{\theta}=0$, and $\frac{\partial}{\partial r} U_{\phi}=0$ at $700-\mathrm{km}$ altitude and $F\left(\mathrm{O}\left({ }^{1} \mathrm{D}\right)\right)=0$ at $1500-\mathrm{km}$ altitude in the both hemispheres.

\section{References}

Abdou, W. A., D. G. Torr, P. G. Richards, M. R. Torr, and E. L. Breig, Results of a comprehensive study of the photochemistry of $\mathrm{N}_{2}^{+}$in the ionosphere, J. Geophys. Res., 89, 9069-9079, 1984.

Adams, N. G., and D. Smith, Product ion distribution for some ionmolecule reactions, J. Phys. B., 9, 1439-1442, 1976.

Albritton, D. L., I. Dotan, W. Lindinger, W. Mc Farland, J. Tellinghuisen, and F. C. Fehsenfeld, Effects of ion speed distributions in flow-drift tube studies of ion-neutral reactions, J. Chem. Phys., 66, 410-421, 1977.

Bailey, G. J., and R. Sellec, A mathematical model of the Earth's plasmasphere and its applications in a study of $\mathrm{He}^{+}$at $L=3$, Ann. Geophysicae, 8, 171-190, 1990.

Banks, P. M., and G. Kockarts, Aeronomy, Academic Press New York, London, 1973.

Barakat, A. R., and R. W. Schunk, $\mathrm{O}^{+}$charge exchange in the polar wind, J. Geophys. Res., 89, 9835-9839, 1984.

Bates, D. R., Recombination in the normal E and F layers of the ionosphere, Planet. Space Sci., 36, 55-63, 1988.

Bilitza, D., Progress report on IRI status, Adv. Space Res., 10, (11)3-(11)5, 1990.

Canoza, A., J. C. Gomet, B. R. Rowe, and J. L. Queffelec, Flowing afterglow Langmuir probe measurement of the $\mathrm{N}_{2}^{+}(v=0)$ dissociative recombination rate coefficient, J. Chem. Phys., 94, 7159-7163, 1991. 
Chang, T., P. G. Richards, and D. G. Torr, Reevaluation of the $\mathrm{O}^{+}\left({ }^{2} \mathrm{P}\right)$ reaction rate coefficients derived from Atmosphere Explorer C observation, J. Geophys. Res., 98, 15589-15597, 1993.

Chen, J. C. Y., Theory of subexcitation electron scattering by molecules II. Excitation and de-excitation of molecular vibration, J. Chem. Phys., 40, 3513-3520, 1964.

Chen, A., R. Johnsen, and M. A. Biondi, Measurements of the $\mathrm{O}^{+}+\mathrm{N}_{2}$ and $\mathrm{O}^{+}+\mathrm{O}_{2}$ reactions rates from 300 to $900 \mathrm{~K}$, Chem. Phys., 69, 2688-2691, 1978.

Cole, K. D., Stable auroral red arcs, sinks for energy of Dst main phase, J. Geophys. Res., 70, 1689-1706, 1965.

Conrad, J. P., and R. W. Schunk, Diffusion and heat flow equations with allowance for large temperature differences between interacting spacies, J. Geophys. Res., 84, 811-822, 1979.

Cornwall, J. M., F. V. Coroniti, and R. M. Thorne, Unified theory of sar-arc formation at the plasmapause, J. Geophys. Res., 76, 4428-4445, 1971.

Dube, L., and A. Herzenberg, Absolute cross sections from the "boomerang model" for resonant electron-molecule scattering, Phys. Rev. A, 20, 194-213, 1979.

Erlandson, R. E., T. L. Aggson, W. R. Hogey, and J. A. Slavin, Simultaneous observations of subauroral electron temperature enhancements and electromagnetic ion cyclotron waves, Geophys. Res. Lett., 20, 1723-1726, 1993.

Fehsenfeld, F. C., The reaction of $\mathrm{O}_{2}^{+}$with atomic nitrogen and $\mathrm{NO}^{+} \mathrm{H}_{2} \mathrm{O}$ and $\mathrm{NO}_{2}^{+}$with atomic oxygen, Planet. Space Sci., 25, 195-200, 1977.

Fehsenfeld, F. C., D. B. Dunkin, and E. E. Ferguson, Rate constants for the reaction of $\mathrm{CO}_{2}^{+}$with $\mathrm{O}, \mathrm{O}_{2}$ and $\mathrm{NO} ; \mathrm{N}_{2}^{+}$with $\mathrm{O}$ and $\mathrm{NO}$; and $\mathrm{O}_{2}^{+}$with NO, Planet. Space Sci., 18, 1267$1269,1970$.

Ferguson, E. E., Comment on "The effect on thermospheric chemistry of a resonant charge-exchange reaction involving vibrationally excited $\mathrm{N}$ ions with atomic oxygen" by W. A. Abdou et al., J. Geophys. Res., 89, 399-400, 1984.

Ferguson, E. E., N. G. Adams, D. Smith, and E. Alge, Rate coefficients at $300 \mathrm{~K}$ for the vibrational energy transfer reactions from $\mathrm{N}_{2}(v=1)$ to $\mathrm{O}_{2}^{+}(v=0)$ and $\mathrm{NO}^{+}(v=0), J$. Chem. Phys., 80, 6095-6098, 1984

Ferziger, J. H., and G. H. Kaper, Mathematical theory of transport processes in gases, North-Holland Amsterdam, London, 1972.

Fok, M.-C., J. U. Kozyra, A. F. Nagy, C. E. Rasmussen, and G. V. Khazanov, Decay of equatorial ring current ions and associated aeronomical consequences, J. Geophys. Res., 98, 19381-19393, 1993.

Fok, M.-C., P. D. Graven, T. E. Moore, and P. G. Richards, Ring current-plasmasphere coupling through Coulomb collisions, in Cross-scale coupling in space plasma Eds. J. L. Horwitz, N. Singh, and J. L. Burch, geophys Monogr. Ser., 93, Washington, pp. 161-171, 1995a.

Fok, M.-C., T. E. Moore, J. U. Kozyra, G. C. Ho, and D. C. Hamilton, Three-dimensional ring current decay model, $J$. Geophys. Res., 100, 9619-9632, 1995 b.

Fox, J. L. and A. Dalgarno, The vibrational distribution of $\mathrm{N}_{2}^{+}$in the terrestrial ionosphere, J. Geophys. Res., 90, 7557-7567, 1985.

Fujimoto, G., A. Nitzan, and E. Weitz, Diffusion of vibrationally excited molecules, Chem. Phys., 15, 217-225, 1976.

Gilmore, F. R., E. Bauer, and J. W. McGowan, A review of atomic and molecular excitation mechanisms in nonequilibrium gases up to 20000 K, J. Quant. Spectrosc. Radiat. Transfer, 9, 157183, 1969

Guberman, S. L., Dissociative recombination of the ground state of $\mathrm{N}_{2}^{+}$, Geophys. Res. Lett., 18, 1051-1054, 1991.

Haddad, G. N., Cross-sections for electron scattering in nitrogen, Austr. J. Phys., 37, 484-494, 1984

Hedin, A. E., MSIS-86 thermospheric model, J. Geophys. Res., 92, 4649-4662, 1987.

Horne, R. B., and R. M. Thorne, On the preferred source location for the convective amplification of ion cyclotron waves, $J$. Geophys. Res., 98, 9233-9247, 1993.
Itikawa, Y., M. Hayashi, A. Ichimura, K. Onda, K. Sakimoto, T. Takayanagi, M. Nakamura, H. Nishimura, and T. Takayanagi, Cross sections for collisions of electrons and photons with nitrogen molecules, J. Phys. Chem. Ref. Data, 15, 985-1010, 1986.

Iwagami, N., and T. Ogawa, Thermospheric NO profilies observed at the diminishing phase of solar cycle 21, Planet. Space Sci., 35, 191-198, 1987.

Johnsen, R., and M. A. Biondi, Laboratory measurements of the $\mathrm{O}^{+}\left({ }^{2} \mathrm{D}\right)+\mathrm{N}_{2}$ and $\mathrm{O}^{+}\left({ }^{2} \mathrm{D}\right)+\mathrm{O}_{2}$ reaction rate coefficients and their ionospheric implications, Geophys. Res. Lett., 7, 401-403, 1980.

Konikov, Y. V., and A. V. Pavlov, On airglow at $630 \mathrm{~nm}$ wavelength in the SAR-arcs region, Ann. Geophysicae, 9, 540-454, 1991.

Krinberg, I. A., and A. V. Tachilin, Ionosphere and plasmasphere (in Russian), Nauka, Moscow, 1984.

Kozyra, J. U., and A. F. Nagy, Ring current decay - coupling of ring current energy into the thermosphere/ionosphere system, $J$. Geomagn. Geoelectr., 43, 285-297, 1991.

Kozyra, J. U., T. E. Gravence, A. F. Nagy, M. O. Chandler, L. H. Brace, N. C. Maynard, D. W. Slater, B. A. Emery, and S. D. Shawhan, Characteristics of a stable auroral red arc events, Geophys. Res. Lett., 9, 973-976, 1982.

Kozyra, J. U., E. G. Shelley, R. H. Comfort, L. H. Brace, T. E. Gravens, and A. F. Nagy, The role of ring current $\mathrm{O}^{+}$in the formation of stable auroral red arcs, J. Geophys. Res., 92, 7487$7502,1987$.

Kozyra, J. U., C. E. Valladares, H. C. Carlson, M. J. Buonsanto, and D. W. Slater, A theoretical study of the seasonal and solar cycle variations of stable auroral red arcs, J. Geophys. Res., 95, 12219-12234, 1990.

LaValle, S. R., and D. D. Elliott, Observations of SAR arcs from OV1-10, J. Geophys. Res., 77, 1802-1809, 1972.

Lee, J. H., J. V. Michael, W. A. Payne, and L. J. Stief, Absolute rate of the reaction of $\left.\mathrm{N}^{4} \mathrm{~S}\right)$ with NO from $190-400 \mathrm{~K}$ with DFRF and FP-RF techniques, J. Chem. Phys., 69, 3069-3073, 1978.

Lindinger, W., F. C. Fehsenfeld, A. L. Schmeltekopf, and E. E. Ferguson, Temperature dependence of some ionospheric ionneutral reactions from 300-900 K, J. Geophys. Res., 82, 47534756, 1974.

Mauclaire, G., R. Derai, S. Fenistein, R. Matx, and R. Johnsen, Thermal energy charge transfer from $\mathrm{He}^{+}$to $\mathrm{O}_{2}$ : kinetic energy, nature, and reactivity of the $\mathrm{O}^{+}$product ions, J. Chem. Phys., 70, 4023-4026, 1979.

McFarland, M., D. L. Albritton, F. C. Fehsenfeld, E. E. Ferguson, and A. L. Schmeltekopf, Energy dependence and branching ratio of the $\mathrm{N}_{2}^{+}+\mathrm{O}$ reaction, J. Geophys. Res., 79, 2925-2926, 1974.

McNeal, R. G., M. E. Whitson, and G. R. Cook, Temperature dependence of the quenching of vibrationally excited nitrogen by atomic oxygen, J. Geophys. Res., 79, 1527-1531, 1974.

Mehr, F. J., and M. A. Biondi, Electron temperature dependence of recombination of $\mathrm{O}_{2}^{+}$and $\mathrm{N}_{2}^{+}$ions with electrons, Phys. Rev., 181, 264-269, 1969.

Newton, G. P., J. C. G. Walker, and P. H. E. Meijer, Vibrationally excited nitrogen in stable auroral red arcs and its effect on ionospheric recombination, J. Geophys. Res., 79, 3807-3818, 1974.

Oppenheimer, M., E. R. Constantinides, K. Kirby-Docken, G. A. Victor, and A. Dalgarno, Ion photochemistry of the thermosphere from Atmosphere Explorer C measurements, J. Geophys. Res., 82, 5485-5492, 1977.

Pavlov, A. V., The binary molecular diffusion coefficients of the neutral components of the upper atmospheres of Earth, Mars, and Venus, (in Russian) Space Res., 19, 82-86, 1981.

Pavlov, A. V., The role of vibrationally excited nitrogen in the ionosphere, Pure Appl. Geophys., 127, 529-544, 1988.

Pavlov, A. V., About the role of vibrationally excited nitrogen in the sabauroral red arc region (in Russian), Geomagn. Aeron., 29, 948-953, 1989.

Pavlov, A. V., Airglow of the upper atmosphere at $630 \mathrm{~nm}$ by rocket data from "Vertical 6 and 7" (in Russian), Geomagn. Aeron., 30, 261-267, 1990. 
Pavlov, A. V., Interpretation of incoherent radio wave scatter data at Millstone Hill during high solar activity conditions, (in Russian), Geomagn. Aeron., 31, 664-668, 1991.

Pavlov, A. V., The role of vibrationally excited nitrogen in the formation of the mid-latitude ionisation trough, Ann. Geophysicae, 11, 479-484, 1993.

Pavlov, A. V., The role of vibrationally excited nitrogen in the formation of the mid-latitude ionospheric storms, Ann. Geophysicae, 12, 554-564, 1994.

Pavlov, A. V., Mechanisms of the electron density depletion in the SAR arc region, Ann. Geophysicae, 14, 211-221, 1996.

Pavlov, A. V., and M. J. Buonsanto, Comparison of model electron densities and temperatures with Millstone Hill observations during undisturbed periods and the geomagnetic storms of 16 23 March and 6-12 April 1990, Ann Geophysicae, 15, 327-344, 1997.

Pavlov, A. V., and A. A. Namgaladze, Vibrationally excited nitrogen in the upper atmosphere. Review paper (in Russian), Geomagn Aeron., 28, 705-721, 1988.

Phillips, L. F., and H. I. Schiff, Mass-spectrometric studies of atom reactions II. Vibrationally excited $\mathrm{N}_{2}$ formed by the reaction of N atoms with NO, J. Chem. Phys., 36, 3283-3286, 1962.

Radzig, A. A., and B. V. Smirnov, The reference book in atomic and molecular physics (in Russian), Atomizdat, Moscow, 1980.

Reed, E. I., and J. E. Blamont, Ogo 4 observations of the September 1967 M-arc, EOS Trans. AGU, 49, 731, 1968.

Rees M. H., and R. G. Roble, Observations and theory of the formation of stable auroral red arcs, Rev. Geophys. Space Phys., 13, 201-242, 1975.

Richards, P. G., An improved algorithm for determining neutral winds from the height of the $\mathrm{F} 2$ peak electron density, $J$. Geophys. Res., 96, 17839-17846, 1991.

Richards, P. G., J. A. Fennelly, and D. G. Torr, EUVAC: A solar EUV flux model for aeronomical calculations, J. Geophys. Res., 99, 8981-8992, 1994. (Correction in J. Geophys. Res., 99, 13283, 1994.)

Seaton, M. J., and D. W. Osterbrock, Relative OII intensities in gaseous nebulae, Astrophys. J., 125, 66-83, 1957.

Schmeltekopf, A. L., E. E. Ferguson, and F. C. Fehsenfeld, Afterglow studies of the reactions $\mathrm{He}^{+}, \mathrm{He}\left(2^{3} \mathrm{~S}\right)$, and $\mathrm{O}^{+}$with vibrationally excited $\mathrm{N}_{2}, J$. Chem. Phys., 48, 2966-2973, 1968.

Schulz, G. J., A review of vibrational excitation of molecules by electron impact at low energies, in Principles of laser plasmas, Ed. G. Berkefi, Interscience, New York, pp. 33-76, 1976.

Slanger, T. G., and G. Black, Electronic-to-vibrational energy transfer efficiency in the $\mathrm{O}\left({ }^{1} \mathrm{D}\right)-\mathrm{N}_{2}$ and $\mathrm{O}\left({ }^{1} D\right)$-CO systems, $J$. Chem. Phys., 60, 468-477, 1974.

Slater, D. W., C. Gurgiolo, J. U. Kozyra, E. W. Kleckner, and J. D. Winningham, A possible energy source to power stable auroral red arcs: precipitating electrons, J. Geophys. Res., 92, 45434552, 1987.
Smith, F. L., and C. Smith, Numerical evaluation of Chapman's c grazing incidence integral ch(X,xi), J. Geophys. Res., 77, 35923597, 1972.

Sobral, J. H. A., H. Takahashi, M. A. Abdu, P. Muralikrishna, Y. Sahai, C. J. Zamlutti, E. R. de Paula, and P. P. Batista, Determination of the quenching rate of the $\mathrm{O}\left({ }^{1} \mathrm{D}\right)$ by $\mathrm{O}\left({ }^{3} \mathrm{P}\right)$ from rocket-borne optical $(630 \mathrm{~nm})$ and electron density data, J. Geophys. Res., 98, 7791-7798, 1993.

Solomon, S. C., P. B. Hays, and V. J. Abreu, The auroral 6300 A emission: observations and modelling, J. Geophys. Res., 93, 9867-9882, 1988.

St.-Maurice, J.-P., and D. G. Torr, Nonthermal rate coefficients in the ionosphere: the reaction of $\mathrm{O}^{+}$with $\mathrm{N}_{2}, \mathrm{O}_{2}$ and $\mathrm{NO}$, J. Geophys. Res., 83, 969-977, 1978.

Streit, G. E., C. J. Howard, A. L. Schmeltekopf, J. A. Davidson, and H. I. Schiff, Temperature dependence of $\mathrm{O}\left({ }^{1} \mathrm{D}\right)$ rate constants for reactions with $\mathrm{O}_{2}, \mathrm{~N}_{2}, \mathrm{CO}_{2}, \mathrm{O}_{3}$, and $\mathrm{H}_{2} \mathrm{O}$, J. Chem. Phys., 65, 4761-4764, 1976

Suchkov, A. F., and Ju. I. Schebeko, The kinetic of the vibrational exchange in the nonequilibrium nitrogen (in Russian), Chem. High Energ. 15, 279-283, 1981.

Taylor, R. L., Energy transfer processes in the stratosphere, Can. J. Chem., 52, 1436-1451, 1974.

Thorne, R. M., and R. B. Horne, The contribution of ion-cyclotron waves to electron heating and SAR-arc excitation near the storm-time plasmapause, Geophys. Res. Lett., 19, 417-420, 1992.

Tobiska, W. K., The empirical solar EUV irradiance model EUV94 (abstract), EOS Trans. AGU, 74(43), 490, 1993.

Tobiska, W. K., Modeled soft X-ray solar irradiance, Solar Phys., 152, 207-215, 1994.

Torr, M. R., and D. G. Torr, Recombination of $\mathrm{NO}^{+}$in the midlatitude trough and the polar ionization hole, J. Geophys. Res., 84, 4316-4320, 1979.

Torr, M. R., and D. G. Torr, The role of metastable species in the thermosphere, Rev. Geophys. Space Phys., 20, 91-144, 1982.

Torr, M. R., D. G. Torr, P. G. Richards, and S. P. Yung, Midand low-altitude model of thermospheric emissions. $1 . \mathrm{O}^{+}\left({ }^{2} \mathrm{P}\right)$ $7320 \mathrm{~A}$ and $\mathrm{N}_{2}\left({ }^{2} \mathrm{P}\right) 3371 \mathrm{~A}$, J. Geophys. Res., 95, 21147-21168, 1990.

Tully, J. C., Collision complex model for spin forbidden reactions: quenching of $\mathrm{O}\left({ }^{1} \mathrm{D}\right)$ by $\mathrm{N}_{2}, J$. Chem. Phys., 61, 61-68, 1974.

Van Zandt, T. E., and T. F. O' Malley, Rate coefficient for the reaction of $\mathrm{O}^{+}$with vibrationally excited $\mathrm{N}_{2}, J$. Geophys. Res., 78, 6818-6820, 1973 .

Viehland, L. A., and E. A. Mason, Statistical-mechanical theory of gaseous ion-molecule reaction in an electrostatic field, J. Chem. Phys., 66, 422-434, 1977.

Walls, F. L., and G. H. Dunn, Measurement of total cross sections for electron recombination with $\mathrm{NO}^{+}$and $\mathrm{O}_{2}^{+}$using ion storage techniques, J. Geophys. Res., 79, 1911-1915, 1974. 